\title{
EL INTERÉS DEL MENOR. CRITERIOS DE DETERMINACION Y APLICACIÓN EN CASOS CONCRETOS*
}

\author{
THE BEST INTERESTS OF THE MINOR. CRITERIA FOR \\ DETERMINATION AND APPLICATION IN SPECIFIC CASES
}

\author{
MARÍA José SAnTOS MoRÓN**
}

\begin{abstract}
Resumen: Este trabajo analiza los criterios introducidos en el nuevo art. 2 LOPJM (modificado por la LO 8/2015 de 22 de julio) con el fin de facilitar la determinación del interés del menor. En primer lugar, pretende ofrecer algunas pautas de carácter general para el supuesto en que unos y otros entran en conflicto. A continuación, se examina el impacto que algunos de estos criterios pueden tener cuando la Administración adopta una medida de protección del menor y con posterioridad se estudian otros criterios de mayor incidencia cuando los representantes de un menor deben adoptar una decisión relativa al mismo por carecer éste de madurez para decidir. En particular se analiza la modificación realizada por las leyes de 2015 en la Ley 41/2002 de Autonomía del paciente y la LO 2/2010 de Salud sexual y reproductiva, que amplían la intervención paterna en la toma de decisiones al tiempo que limitan, en cierta medida, la capacidad de las menores para decidir por sí mismas.
\end{abstract}

Palabras clave: Interés superior, permanencia en la familia, derecho a ser oído, autonomía, consentimiento informado, aborto.

Abstract: This article analyses the criteria incorporated into the new art. 2 LOPJM with the purpose of facilitating the determination of the minor's best interests. Firstly, it aims to provide some general guidelines that are applicable in cases where conflict between these criteria arise. The article goes on to examine the impact that some of these criteria may have when the Administration adopts a measure to protect a minor and then proceeds to study other criteria of higher incidence when the minor's representative must make a decision regarding the minor, due to his lack of maturity. In particular, the modification made by the laws of 2015 in Law 41/2002 on

* http://doi.org/10.15366/rjuam2018.38.008.

Fecha de recepción: 30 de octubre de 2018.

Fecha de publicación: 19 de diciembre de 2018.

** Catedrática de Derecho civil de la Universidad Carlos III de Madrid. Correo electrónico: mjs@der-pr. uc3m.es. Este trabajo se ha realizado en el marco del de Cooperación UAM-Santander con América Latina «Libertad de autodeterminación en las relaciones familiares y sus límites como desafío del Derecho de Familia del siglo XXI en España y América Latina» (CEAL-AL/2017-20). Un resumen del mismo fue presentado en el Seminario de Profesores del AFDUAM el 17 de mayo de 2018 y en el Congreso Internacional «Desafíos actuales de la Autonomía de la voluntad en las relaciones familiares y sus límites» que tuvo lugar los días 25-27 de septiembre 2018 en la Universidad Adolfo Ibáñez de Chile (Campus Santiago de Chile y Viña del Mar). 
Patient Autonomy and LO 2/2010 on Sexual and Reproductive Health is analysed, because these amendments broaden paternal intervention in decision-making, while limiting, to some extent, the capacity of minors to decide for themselves.

Keywords: Best interests, permanence in the family, right to be heard, autonomy, informed consent, abortion.

SUMARIO: I. INTRODUCCIÓN; EL NUEVO ART. 2 LOPJM; II. CRITERIOS DE VALORACIÓN DEL INTERÉS DEL MENOR: PONDERACIÓN EN CASO DE CONFLICTO ENTRE ELLOS; III. APLICACIÓN PRÁCTICA DE ALGUNOS CRITERIOS EN LA TOMA DE DECISIONES; 1. El criterio recogido en el art. 2.2.c) y su incidencia en la adopción de medidas administrativas de protección del menor; 2. Los criterios b) y d) y la prestación del consentimiento al tratamiento médico; A. La prestación del consentimiento al tratamiento médico por menores de edad tras la reforma de 2015; B. La modificación de la regulación del aborto de las menores de edad; IV.RECAPITULACIÓN; V. BIBLIOGRAFÍA.

\section{INTRODUCCIÓN. EL NUEVO ART. 2 LOPJM}

Como es sabido, desde hace tiempo, la ley viene potenciando la consideración del menor como un sujeto titular de derechos, que puede ejercerlos autónomamente a medida que va alcanzando ciertas condiciones de madurez. Muestra de esta tendencia son el art. 162,1 CC; el art. 3 LO 1/1982 de protección civil del derecho al honor, la intimidad personal y familiar y a la imagen; la Ley 1/96 de Protección jurídica del menor, o el art. 9 Ley 41/2002 -normas, estas dos últimas, que han sufrido ciertas modificaciones como consecuencia de las leyes de reforma del sistema de la infancia y la adolescencia-.

De dichas normas se deduce que corresponde a los menores ejercer sus derechos de la personalidad si tienen suficiente capacidad natural; esto es, si tienen la madurez y el discernimiento suficiente para entender el alcance y consecuencias de la decisión a adoptar ${ }^{1}$. La posibilidad, por parte de los menores, de ejercer sus derechos fundamentales está estrechamente ligada con el principio de interés del menor, ya que precisamente la protección de dicho interés pasa por fomentar su derecho al libre desarrollo de la personalidad y permitirles el ejercicio de tales derechos a medida que van adquiriendo madure $z^{2}$.

1 Por todos, SANTOS MORÓN, M.J., «Menores y derechos de la personalidad. La autonomía del menor», AFDUAM, vol. 15, 2011, pp. 64-69.

2 La doctrina viene relacionando, desde hace tiempo, el concepto del interés del menor con la protección de sus derechos fundamentales, que va unida al reconocimiento de su autonomía como sujetos y progresiva posibilidad de ejercitarlos. La LO 1/96 ya señalaba en su Exposición de Motivos que «mejor forma de garantizar social y jurídicamente la protección a la infancia es promover su autonomía como sujetos» y la Observación núm. 14 (2013) del Comité de los Derechos del Niño dice en sus párrafos 4 y 51 que el objetivo del concepto del interés superior del niño «es garantizar el disfrute pleno y efectivo de todos los derechos reconocidos en la convención y el desarrollo holístico del niño». ROCA I TRÍAS, E., «El interés del menor como factor de progreso y unificación», RJC, vol. 93, núm. 4, (1994), pp. 107-109122; RIVERO HERNÁNDEZ, F., El 
No obstante, cuando el menor carece de la suficiente madurez, es inevitable que sean otros quienes deban proteger y, en su caso, ejercer los derechos que les corresponden. Y en este caso el principio del interés del menor opera como guía o criterio rector en la toma de la decisión de que se trate. La primacía del interés superior del menor en la adopción de decisiones que le afecten viene establecida con carácter general en el art. 2 LOPJM, tanto en relación con las decisiones de padres o representantes del menor ${ }^{3}$, como en relación con cualquier acción o medida concerniente a los menores que puedan adoptar las instituciones públicas o privadas o los tribunales.

El presente trabajo pretende abordar la concreción del concepto del interés del menor tomando como base dos tipos de situaciones:

Aquellas en que un sujeto, normalmente una autoridad administrativa o judicial, tiene que adoptar una decisión que afecta de manera decisiva al menor (v. gr. declaración de desamparo y tutela de las administraciones públicas; guarda y custodia de los progenitores en casos de crisis matrimonial, etc.).

Aquellas otras en que un sujeto, normalmente los padres o representantes legales del menor, tienen que adoptar una decisión en lugar del menor al no estar este en condiciones de decidir por sí mismo ${ }^{4}$.

Tanto en un caso como el otro la complejidad estriba, como fácilmente puede colegirse, en saber en qué consiste el interés del menor; que es, por antonomasia, un concepto jurídico indeterminado de difícil concreción ${ }^{5}$. En este sentido, el art. 2 de la LOPJM de 1996 ha sido

interés del menor, Madrid (Dykinson), 2000, p. 199; TORRES PEREA, J., Interés del menor y Derecho de Familia. Una perspectiva multidisciplinar, Madrid (Iustel), 2009, p. 28; MORENO ANTÓN, M., «La libertad religiosa del menor de edad en el contexto sanitario», AFDUAM, vol. 15, 2011, p. 98; DE LAMA AYMÁ, A., La protección de los derechos de la personalidad del menor de edad, Valencia (Tirant lo Blanch), 2006, pp. 95-97; NAVAS NAVARRO, S., «El bienestar y el interés del menor desde una perspectiva comparada», en CABANILLAS SÁNCHEZ, A. (coord.), Estudios Jurídicos en Homenaje al profesor Díez-Picazo, t. I, Madrid (Civitas), 2003, pp. 693, 707, si bien intenta diferenciar entre el «bienestar» y el «interés» del menor.

3 Aunque el art. 2.1 LOPJM no menciona expresamente a los padres o representantes me parece evidente que están comprendidos en su ámbito de aplicación. De esta opinión, GUILARTE MARTÍN-CALERO, C., «La configuración del interés del menor ex art. 2 LOPJM y su posible aplicación a la determinación del interés de la persona con discapacidad intelectual o mental: una propuesta», en MAYOR DEL HOYO, M.V. (dir.), $E l$ nuevo régimen jurídico del Menor, Cizur Menor (Thomson Aranzadi), 2017, p. 496.

El señalado precepto dispone que «todo menor tiene derecho a que su interés superior sea valorado y considerado como primordial en todas las acciones y decisiones que le conciernan, tanto en el ámbito público como privado». Además, debe tenerse en cuenta que el art. 154.2 CC exige que los padres actúen en interés del menor y de acuerdo con su personalidad. Esto implica que, cuando los padres, en ejercicio de su deber de velar por el menor, deben adoptar decisiones relativas a sus derechos de la personalidad (art. 162,1 segundo inciso CC), dicha decisión debe guiarse por el criterio del interés de menor.

4 En este caso, como indica DE LAMA AYMÁ, A., La protección de los derechos de la personalidad del menor de edad, cit., p. 98, «el desarrollo de la personalidad del menor se canaliza a través de la actuación de los padres que actúan como intérpretes de la personalidad del hijo».

5 Recordemos, en este sentido, las palabras de RIVERO HERNANDEZ, F., El interés del menor, cit., p. 82 , al preguntarse «en qué consiste el interés del menor a la hora de determinar, por ejemplo, si se queda 
modificado por la LO 8/2015 de 22 de julio $^{6}$, con el fin de establecer criterios específicos dirigidos a facilitar la determinación de dicho interés en cada caso concreto ${ }^{7}$. Para ello se ha tenido en cuenta, según se indica en el preámbulo de esta última ley, la jurisprudencia del TS y los criterios de la Observación General núm. 14 de 29 de mayo de 2013 del Comité de Naciones Unidas de Derechos del Niño.

El nuevo precepto introduce una serie de criterios generales que han de ser tomados en consideración «a efectos de la interpretación y aplicación en cada caso del interés superior del menor», si bien se indica que no se trata de una lista tasada, ya que podrán utilizarse otros criterios que vengan establecidos por la legislación aplicable o resulten adecuados en el caso concreto. Los criterios recogidos en el citado precepto son, sintéticamente, los siguientes:

a) La protección del derecho a la vida, supervivencia, desarrollo del menor y satisfacción de sus necesidades básicas ${ }^{8}$.

b) La consideración de sus deseos, sentimientos y opiniones, reconociéndose su derecho a participar en la concreción de su interés de acuerdo con su edad y madurez $z^{9}$

c) La conveniencia de que su vida y desarrollo tenga lugar en un entorno familiar adecuado, debiendo priorizarse la permanencia en su familia de origen y la conservación de sus lazos familiares

con su padre o con su madre tras la crisis matrimonial, o para aprobar el juez una adopción, o para decidir los padres si es bautizado o circuncidado, si estudia o entra a trabajar en un taller, si se somete a una intervención de cirugía estética sobre la que discuten sus padre y madre».

6 Como se sabe, la indicada LO 8/2014 de 22 de julio, así como la Ley 26/2014 de 28 de julio, ambas de «modificación del sistema de protección de la infancia y la adolescencia», han modificado numerosos preceptos de la LOPJM, pero también del CC, la LEC y la Ley de Adopción Internacional (además de algunas otras normas) dando lugar a importantes cambios en el sistema público de protección de menores. En el preámbulo de ambas leyes (apartado I) se indica que una y otra buscan garantizar a los menores una protección uniforme en todo el territorio español, que sirva de marco o referencia a las CCAA en el desarrollo de su respectiva legislación.

7 Es evidente que lo que se entienda por «interés del menor» ha de ser valorado caso por caso atendiendo a la situación en la que se encuentre el menor, las circunstancias concurrentes y también el tipo de decisión que deba adoptarse, pues no es lo mismo, por poner un ejemplo, decidir si el menor debe ser apartado de sus progenitores que si debe o no someterse a una operación quirúrgica.

8 Observa GUILARTE MARTÍN-CALERO, C., «La configuración del interés del menor ex art. 2 LOPJM y su posible aplicación a la determinación del interés de la persona con discapacidad intelectual o mental: una propuesta», cit., p. 498, que se trata de garantizar, además del derecho a la vida y al desarrollo del menor, su bienestar, si bien el legislador, en lugar de usar ese término, describe los aspectos que lo integran según la Observación General núm. 14 («necesidades materiales, físicas, educativas y emocionales básicas, así como su necesidad de afecto y seguridad»). En cuanto al concepto de «desarrollo» del menor, la Observación General núm. 5 lo configura como un concepto holístico «que abarca el desarrollo físico, mental, espiritual, moral, psicológico y social del niño».

9 Para garantizar que el menor pueda expresar su opinión y participar en la toma de decisiones que le afecten el art. 9 LOPJM regula el derecho del menor «a ser oído y escuchado», indicando que deben tenerse en cuenta «debidamente» sus opiniones «en función de su edad y madurez». Se considera que el menor tiene madurez para ser escuchado en todo caso, cuando tiene 12 años cumplidos (art. 9.2) pero ello no implica que no deba escucharse a menores de edad inferior, ya que el propio artículo 9.2 indica que la madurez habrá de valorarse por personal especializado teniendo en cuenta la capacidad del menor para comprender y evaluar el asunto de que se trate. 
d) La preservación de su identidad, cultura, religión, convicciones, orientación e identidad sexual o idioma del menor, reconociéndose su derecho a no ser discriminado por estas u otras condiciones como la discapacidad.

\section{CRITERIOS DE VALORACIÓN DEL INTERÉS DEL MENOR: PONDERACIÓN EN CASO DE CONFLICTO ENTRE ELLOS}

Los criterios mencionados han de integrar el significado que ha darse en cada caso al «interés del menor» a fin de orientar la decisión de que se trate. Respecto de ellos, cabe hacer algunas consideraciones de orden general.

En primer lugar, hay que señalar que el conjunto de criterios enunciados pone de manifiesto que, desde la perspectiva del legislador, la valoración del interés del menor no puede hacerse ni desde un punto de vista exclusivamente objetivo, ni tampoco desde un punto de vista puramente subjetivo. En efecto, a la hora de determinar qué es lo más beneficioso para el menor, puede adoptarse una postura objetiva, que tenga en cuenta los valores superiores del ordenamiento y lo que la conciencia social considera más adecuado en cada momento, o una postura subjetiva, que dé primacía a las opiniones, deseos y convicciones del menor, con el fin de adoptar la decisión que más se acomode a sus preferencias o la que más se asemeje a la que hubiera adoptado el menor de haber podido decidir por sí mismo ${ }^{10}$.

El peligro que presenta la primera postura es, de un lado, la posible inexistencia de consenso sobre ciertos valores, lo que puede dificultar saber qué se considera objetivamente mejor para el menor y, de otro, la posibilidad de que el intérprete se limite a aplicar sus propias convicciones personales al enjuiciamiento de la cuestión ${ }^{11}$.

Pero la toma en consideración de los deseos y opiniones del menor tampoco está exenta de riesgos porque los deseos del menor no siempre pueden coincidir con lo que objetivamente pueda considerarse más beneficioso para él ${ }^{12}$. Si por ejemplo, un menor manifiesta su deseo de no acudir al colegio ni recibir formación básica (lo cual, por otra parte, no es descabellado que suceda), no parece que tal deseo pueda ser tomado en consideración a la hora de decidir si ser escolarizado redunda en su mejor interés.

10 Vid., por ej., las apreciaciones de RIVERO HERNÁNDEZ, F., El interés del menor, cit., pp. 74 y ss. sobre estas dos posibilidades.

11 RIVERO HERNÁNDEZ, F., El interés del menor, cit., pp. 76, 77, alerta sobre la falibilidad «de los criterios presentados como grandes valores, con pretensión de objetivos» indicando que en la práctica son criterios y valores personales de quien toma la decisión. No hay, añade «verdaderas ideas o valoraciones generales (o muy pocas) con validez presuntamente objetiva y universal del interés del menor, pues es evidente que en la mayor parte de los casos difieren según la persona llamada a pronunciarse». NUÑEZ ZORRILLA, M.C. «El interés superior del menor en las últimas reformas llevadas a cabo por el legislador estatal en el sistema de protección a la infancia y a la adolescencia», en Persona y Derecho, vol. 73, núm. 2., 2015, p. 129, alude asimismo a la tendencia del intérprete a aplicar sus propias convicciones.

12 RIVERO HERNÁNDEZ, F., El interés del menor, cit., p. 98. 
La opción adoptada por el legislador da entrada a ambas perspectivas, objetiva y subjetiva, a la hora de determinar qué se entiende por interés del menor. Además, se garantiza que el menor pueda expresar sus deseos, opiniones y convicciones ideológicas, culturales, etc., desarrollando, en el art. 9, el derecho del menor a ser «oído y escuchado sin discriminación alguna por edad, discapacidad o cualquier otra circunstancia, tanto en el ámbito familiar como en cualquier procedimiento administrativo, judicial o de mediación [...] teniéndose debidamente en cuenta sus opiniones, en función de su edad y madurez»» ${ }^{13}$.

Por consiguiente, el intérprete deberá tener en cuenta, de un lado, ciertos valores que se consideran prioritarios, como la preservación de la vida del menor, la satisfacción de sus necesidades, su adecuado desarrollo y el mantenimiento de relaciones con su familia de origen (letras a y c). De otro, los deseos y opiniones del menor, así como sus convicciones religiosas o de otro tipo y su identidad cultural y sexual (letras b y d).

No obstante, es claro que los mencionados criterios pueden ser de mayor o menor relevancia en función del tipo de decisión de que se trate ${ }^{14}$, y también es evidente que en la práctica unos y otros pueden entrar en colisión. Pensemos por ejemplo en el supuesto en que las convicciones religiosas de un menor puedan poner en peligro su vida (el caso típico de los testigos de Jehová), que sus ideas o convicciones culturales puedan poner en peligro su salud (v. gr. menor vegana), o que sus deseos puedan poner en peligro su formación y desarrollo futuro (menor que rechaza acudir al colegio).

La dificultad en estos casos viene dada porque, si el respeto a los deseos, opiniones, convicciones e identidad cultural y sexual del menor forma parte de lo que el legislador considera como su «interés», cabe preguntarse en qué caso estará autorizado el intérprete a desatenderlos. Téngase en cuenta que el precepto que comentamos no establece en principio ningún tipo de jerarquía entre los criterios señalados ni por consiguiente cabe deducir del mismo que deban prevalecer los criterios que podemos catalogar como «objetivos», frente a los subjetivos.

De hecho, la doctrina observa que cuando la decisión adoptada difiera de la opinión o deseos expresados por el menor deberá explicarse la razón que lo justifica ${ }^{15}$, y ello es lógico

13 Este artículo está en consonancia con el art. 12 de la Convención de Derechos del Niño, en cuya virtud «los Estados deben asegurar que el niño pueda expresar su opinión en las cuestiones que les afecten y debe darse mayor peso a sus opiniones en función de su edad y madurez».

14 Parece evidente, por ej., que cuando se discute sobre la custodia del menor en caso de crisis matrimonial tiene especial relevancia el garantizar que la vida del menor se desarrolle en un entorno familiar libre de violencia. Esa circunstancia, sin embargo, no es importante cuando se trata de consentir un tratamiento médico. En este último caso lo fundamental es la preservación del derecho a la vida del menor, pero esta consideración puede no ser tan relevante cuando se trata, por ej., de declarar el desamparo del menor, en cuyo caso no suele estar en juego la vida del menor sino más bien su desarrollo y la satisfacción de sus necesidades básicas.

15 NÚÑEZ ZORRILLA, M.C., «El interés superior del menor en las últimas reformas llevadas a cabo por el legislador estatal en el sistema de protección a la infancia y a la adolescencia» cit., pp. 131, 133; HUETE NOGUERAS, J.J., «Desafíos de la nueva ley: derechos de los menores y papel del Ministerio Fiscal», en MAYOR DEL HOYO, M. V. (dir.), El nuevo régimen jurídico del menor, La reforma legislativa de 2015, Cizur Menor (Thomson-Aranzadi), 2017, p. 92. 
porque el nuevo art. 2.5 LOPJM, exige que cualquier decisión relativa a un menor incluya en su motivación los criterios utilizados y los elementos aplicados al ponderar los criterios entre $s i^{16}$. De ahí cabe deducir que cualquier decisión que haga prevalecer unos criterios sobre otros deberá explicitar por qué en ese caso concreto se considera que unos criterios reflejan el interés del menor en mayor medida que otros.

Para facilitar la labor de ponderación de los criterios enunciados en el art. 2.2, el propio art. 2, enumera, en su apartado 3, una serie de elementos a tener en cuenta, como son: la edad y madurez del menor; la necesidad de garantizar su igualdad; el efecto del transcurso del tiempo en su desarrollo; la necesidad de estabilidad de las soluciones que se adopten; la preparación del tránsito a la edad adulta, y aquellos otros que puedan considerarse pertinentes en el supuesto concreto. Sin embargo, los mencionados elementos, que según el indicado art. 2,3 deben ser valorados conjuntamente conforme a los principios de necesidad y proporcionalidad $^{17}$, salvo por lo que respecta al relativo a la edad y madurez del menor, no parecen a priori de mucha ayuda para resolver la cuestión planteada. Aunque es evidente que una adecuada respuesta al dilema expresado debe atender a las circunstancias concurrentes en cada caso concreto, creo que como punto de partida deben tenerse en cuenta algunas ideas.

En primer lugar, del conjunto de la regulación articulada por las Leyes de 2015 de Reforma de la Infancia y la Adolescencia cabe deducir que la protección del derecho a la vida del menor es considerada como la regla prevalente frente a cualquier otra consideración. Esto se deduce de las modificaciones realizadas por la Ley 26/2015 en la Ley 41/2002 de Autonomía del Paciente, y particularmente en su art. $9^{18}$, y de lo establecido en el art. 17.10 LOPJM $^{19}$, normas sobre las que volveré con posterioridad.

16 Esta regla está en consonancia con lo establecido en el párrafo 14, letra b) de la Observación General núm. 14 del Comité de Derechos del niño que dispone que todas las decisiones judiciales y administrativas deben dejar patente que el interés superior del niño «ha sido una consideración primordial» lo que «incluye explicar cómo se ha examinado y evaluado el interés superior del niño».

17 Con tal exigencia de «necesidad y proporcionalidad» se pretende, de acuerdo con dicho precepto, que «la medida que se adopte en el interés superior del menor no restrinja o limite más derechos que los que ampara».

18 La DF 2 de la Ley 26/2014 ha modificado el art. 9 de la Ley 41/2002 en un sentido que, lleva a concluir que, desde el punto de vista del legislador, la vida del menor es considerada el interés prioritario. Con independencia de las críticas que, en mi opinión, merece la restricción a la capacidad del menor mayor de 16 años para emitir el consentimiento cuando se trata de intervenciones de grave riesgo (art. 9.4), el apartado 6 de dicho precepto dispone ahora que «en los casos en los que el consentimiento haya de otorgarlo el representante legal o las personas vinculadas por razones familiares o de hecho en cualquiera de los supuestos descritos en los apartados 3 a 5 , $l a$ decisión deberá adoptarse atendiendo siempre al mayor beneficio para la vida o salud del paciente».

19 El 17.10 LOPJM dispone que «la negativa de los progenitores, tutores, guardadores o acogedores a prestar el consentimiento respecto de los tratamientos médicos necesarios para salvaguardar la vida o integridad física o psíquica de un menor constituye una situación de riesgo», en cuyo caso las autoridades sanitarias deberán poner en conocimiento de la autoridad judicial los hechos en cuestión. Esta norma no hace ninguna excepción por lo que cabe entender que incluso en el supuesto en que la negativa de los progenitores, tutores, etc., sea conforme con la opinión del propio menor procede derivar la cuestión a la autoridad judicial. 
Más discutible me parece que deba considerarse prevalente la protección del «desarrollo del menor» y la «satisfacción de sus necesidades básicas» ${ }^{20}$ frente a criterios como los deseos del menor o su identidad religiosa, cultural, etc. Y ello porque una y otro son nociones indeterminadas que requieren una nueva labor de concreción, y para saber qué es lo más beneficioso para el desarrollo del menor o cómo se satisfacen mejor sus necesidades educativas, emocionales o afectivas, no creo que pueda prescindirse de sus deseos, sentimientos, opiniones, cultura, religión o identidad sexual, pues estos aspectos influyen decisivamente en su desarrollo y necesidades.

Ahora bien, con independencia de lo indicado, el peso que ha de darse a los deseos, sentimientos y opiniones del menor e, igualmente, a sus convicciones culturales, religiosas o de otro tipo e incluso a su identidad sexual varía en función de la edad del menor. Es evidente que, cuanto mayor sea el menor, más relevancia ha de darse a su postura ${ }^{21}$ y más difícil será, por consiguiente, justificar la adopción de una medida o una decisión contraria a los deseos, opiniones o identidad del menor ${ }^{22}$. Así resulta, tanto del propio art. 2.2 letra b), que hace referencia al derecho del menor «a participar progresivamente, en función de su edad, madurez, desarrollo y evolución personal, en el proceso de determinación de su interés superior» como del apartado 3 del art. 2 que indica que los criterios en él enunciados deberán ponderarse teniendo en cuenta «la edad y madurez del menor». La misma idea aparece en el art. 9.1 relativa al derecho del menor a ser «oído y escuchado» que indica que deberá tenerse en cuenta «debidamente» sus opiniones «en función de su edad y madurez».

Por otra parte, en la aplicación del concepto de «interés del menor» cabe distinguir entre aquellas decisiones que se adoptan por una autoridad administrativa o judicial y afectan al menor y aquellas otras que se adoptan por un tercero -habitualmente los padres o tutor- en sustitución del propio menor. Esta distinción está en cierto modo conectada con la diferencia que plantean algunos autores entre derechos de libertad (liberty rights) y derechos de bienestar (welfare rights) ${ }^{23}$. Por lo general cuando una autoridad

20 GUILARTE MARTÍN-CALERO, C., «El interés superior del niño: La nueva configuración del art. 2 de la LO de 15 de enero, de Protección Jurídica del Menor», en CABEDO MALLOL, V. y RAVETLLAT BALLESTÉ, I. (coords.), Comentario sobre las leyes de reforma del sistema de protección de la infancia y la adolescencia, Valencia (Tirant lo Blanch), 2016, p. 118, opina que el primer criterio recogido en el art. 2 «es el principal elemento a tener en cuenta por el intérprete y en principio parece de carácter prevalente frente a cualesquiera otros». Lo mismo dice esta misma autora en GUILARTE MARTÍN-CALERO, C., «La configuración del interés del menor ex art. 2 LOPJM y su posible aplicación a la determinación del interés de la persona con discapacidad intelectual o mental: una propuesta», cit., p. 498. En mi opinión esto es cierto en relación con el derecho a la vida, pero dudoso respecto al desarrollo y satisfacción de las necesidades del menor.

21 En este sentido NUÑEZ ZORRILLA, M.C., «El interés superior del menor en las últimas reformas llevadas a cabo por el legislador estatal en el sistema de protección a la infancia y a la adolescencia», cit., p. 129.

22 Señala NUÑEZ ZORRILLA, M.C., «El interés superior del menor en las últimas reformas llevadas a cabo por el legislador estatal en el sistema de protección a la infancia y a la adolescencia», cit., p. 131, que la decisión que difiera de la opinión del niño deberá exponer con claridad la razón por la que se ha tomado.

23 JONES. P. y WELCH S., Rethinking Children's Rights, $2^{\mathrm{a}}$ ed., Londres-Nueva York (Bloomsbury), 2018, pp. 42 y ss. 
administrativa o judicial adopta una medida que afecta al menor lo hace para garantizar la protección o el bienestar de este ${ }^{24}$ y en cumplimiento del art. 39 CE. En cambio, en el segundo supuesto, cuando los padres o representantes del menor deben tomar una decisión en sustitución de este, porque el menor, debido a su falta de madurez, no puede adoptarla por sí mismo, lo que está en juego es, por lo general, el ejercicio de derechos fundamentales del propio menor, cuyo núcleo fundamental es, precisamente, la libertad, el derecho de autodeterminación.

Teniendo esto en cuenta, cuando se trata de adoptar decisiones relativas a derechos del menor en su lugar (v. gr. consentimiento a tratamientos médicos; consentimiento a la intromisión en sus derechos a la intimidad o imagen; ejercicio de prácticas religiosas, etc.) es clara la necesidad de respetar en la mayor medida posible sus deseos e inclinaciones personales. Y no solo por la propia lógica de la situación (el núcleo básico de los derechos fundamentales es el derecho de autodeterminación del individuo) sino porque el art. 154.2 CC obliga a los padres a ejercer la patria potestad respetando la personalidad del menor ${ }^{25}$.

En cualquier caso, con independencia de estas consideraciones generales, lo cierto es que el alcance y relevancia de los distintos criterios enunciados en el art. 2 LOPJM, especialmente en el supuesto en que entren en conflicto unos y otros, solo puede apreciarse analizando casos concretos. A continuación voy a examinar, en primer lugar, el criterio recogido en la letra c), que hace referencia a la conveniencia de que la vida del menor se desarrolle en un entorno familiar adecuado, debiendo priorizarse la permanencia en su familia de origen y preservarse el mantenimiento de sus relaciones familiares ${ }^{26}$. Como fácilmente puede colegirse, este criterio va a entrar en juego, por lo general, en situaciones en las que una autoridad, administrativa o judicial debe adoptar una medida que afecta al menor, siendo menos probable que opere cuando los representantes legales del menor toman una decisión relativa a derechos de la personalidad del menor por carecer este de la suficiente madurez. Con posterioridad me referiré a los criterios introducidos en las letras b) y d), que son de especial interés precisamente en este último ámbito, y lo haré en relación con el supuesto del consentimiento al tratamiento médico.

24 Así, se incluyen entre esos «derechos de bienestar» el mantenimiento de un estándar de vida básico, cuidados médicos, educación, derecho al descanso y al ocio, participación en la vida cultura, etc., JONES P. y WELCH S., Rethinking Children's Rights, cit., p. 44.

25 DE LAMA AYMÁ, A. La protección de los derechos de la personalidad del menor, cit., pp. 98, 101.

26 La letra c del art. 2 dice lo siguiente: «La conveniencia de que su vida y desarrollo tenga lugar en un entorno familiar adecuado y libre de violencia. Se priorizará la permanencia en su familia de origen y se preservará el mantenimiento de sus relaciones familiares siempre que sea posible y positivo para el menor. En caso de acordarse una medida de protección, se priorizará el acogimiento familiar frente al residencial. Cuando el menor hubiera sido separado de su núcleo familiar, se valorarán las posibilidades y conveniencia de su retorno, teniendo en cuenta la evolución de la familia desde que se adoptó la medida protectora y primando siempre el interés y las necesidades del menor sobre las de la familia». 


\section{APLICACIÓN PRÁCTICA DE ALGUNOS CRITERIOS EN LA TOMA DE DECISIONES}

\section{El criterio recogido en el art. 2.2. c) y su incidencia en la adopción de medidas administrativas de protección del menor}

Para interpretar el interés superior del menor el criterio c) del art. 2.2 ordena atender a «la conveniencia de que su vida y desarrollo tenga lugar en un entorno familiar adecuado y libre de violencia», y continúa diciendo que «se priorizará la permanencia en su familia de origen y se preservará el mantenimiento de sus relaciones familiares siempre que sea posible y positivo para el menor [...]». Esta afirmación tiene especial interés en el ámbito de las medidas administrativas de protección de menores y en particular en los casos de desamparo.

De acuerdo con la nueva redacción del art. 2, la permanencia en la familia de origen y el mantenimiento de relaciones familiares integra el contenido de la noción de «interés del menor». Es decir, esa situación es la que legalmente se considera beneficiosa para el menor. De hecho, el nuevo art. 172 ter $\mathrm{CC}$ dice ahora, en su párrafo segundo, que en caso de medidas de guarda administrativa debe priorizarse la reintegración en la propia familia (antes decía que debía «procurarse» la reinserción cuando no fuese contraria a su interés). No obstante, aunque como regla esta es la situación más beneficiosa para el menor, el propio precepto contempla la posibilidad de que la misma no sea «positiva» para el menor.

Sin embargo, ha de entenderse que esta es la excepción y como tal excepción debe estar convenientemente justificada. Esto implica que la no permanencia o reintegración en la familia de origen ha de basarse en la puesta en peligro de otros valores o elementos que integran el interés del menor. Si se tiene en cuenta que donde mejor puede preservarse la identidad cultural, religiosa, idiomática, etc. (art. 2.2.d) del menor es en su familia de origen, parece claro que solo estará justificada la separación del menor de su familia cuando esté en peligro su derecho a la vida, su desarrollo y la satisfacción de sus necesidades básicas (art. 2.2.a), peligro que debe ser lo suficientemente grave como para justificar que se desconozcan aquellos otros elementos que integran el contenido del interés del menor (entre los que también puede estar el deseo del menor de no separarse de su familia biológica).

De lo dicho se desprende, en mi opinión, que con base en la nueva redacción del art. 2.2 LOPJM, no puede (o no debe) mantenerse la doctrina jurisprudencial que, en relación con la posible reinserción del menor en su familia de origen tras una declaración de desamparo (seguida, habitualmente, de acogimiento familiar), venía considerando, como elementos contrapuestos, el interés del menor y la reinserción familiar.

Ejemplo paradigmático de este planteamiento es la conocida STS de 31 de julio de 2009 (RJ 2009/4581). En el caso enjuiciado la Audiencia había revocado la declaración de desamparo de una menor, que se encontraba en situación acogimiento preadoptivo, por en- 
tender que no estaba justificada inicialmente tal resolución ${ }^{27}$. El TS, sin embargo, consideró que, con independencia de las circunstancias que motivaron la declaración de desamparo y pese a haber evolucionado la madre biológica positivamente, debido al tiempo transcurrido y la integración del menor en la familia de acogida, no procedía el retorno a su familia biológica ${ }^{28}$. Para argumentar tal conclusión, e impedir el regreso del menor a su familia de origen, cuando probablemente nunca debió haber salido de ella, sostuvo que, frente a la reinserción familiar, el legislador otorga «superior jerarquía» al deber de perseguir el interés del menor. Señala esta sentencia que «ambos principios o directrices pueden entrar en contradicción» y en tal caso, prevalece el deber de perseguir el interés del menor pues «la directriz que ordena procurar la reinserción familiar» (se hacía referencia a la anterior redacción del art. 172.4 CC) se subordina expresamente a dicho interés (FJ 6. ${ }^{\circ}{ }^{29}$.

27 La SAP recurrida había entendido que la desatención de la menor no era tan grave como para justificar el desamparo. Se trataba más bien de una situación de riesgo, pese a lo cual la Administración no intentó corregir la situación y actuó con una urgencia innecesaria constituyendo acogimiento familiar preadoptivo y privando a la madre y abuela biológicas de derecho de visitas.

28 En esta sentencia el TS analiza dos cuestiones: a) si debe examinarse la declaración de desamparo atendiendo a las circunstancias que concurrían en el momento inicial o debe tomarse también en consideración el posible cambio de circunstancias acaecido con posterioridad y b) cómo debe ponderarse el interés del menor en relación con la posible reinserción en la familia. A la primera cuestión responde afirmando que el art. 413 LEC admite excepciones, como la de los procesos relativos a menores donde, en aras de su interés, puede contemplarse el cambio de circunstancias producido con posterioridad a la declaración de desamparo con el fin de determinar si los padres se encuentran en condiciones de asumir nuevamente la patria potestad. A la segunda cuestión responde en el sentido indicado en el texto. Pero además señala, en un párrafo citado frecuentemente por otras sentencias, que, para restablecer la unidad familiar es necesario que se den «condiciones que supongan la eliminación del riesgo de desamparo del menor y compensen su interés en que se mantenga la situación de acogimiento familiar si su integración en ella y en el entorno es satisfactoria, si se han desarrollado vínculos afectivos con ella, si obtiene en la familia de acogida los medios necesarios para su desarrollo físico y psíquico, si se mantienen las referencias parentales del menor con la familia biológica y si el retorno al entorno familiar biológico comporta riesgos relevantes de tipo psíquico» (FJ 6. ${ }^{\circ}$, último párrafo).

La doctrina ha criticado el planteamiento de esta sentencia indicando que los requisitos exigidos para el reingreso en la familia son de imposible cumplimiento. Si, pese a haber evolucionado positivamente la familia de origen, esta debe «compensar» las condiciones existentes en la familia de acogida y debe tenerse en cuenta el tiempo transcurrido, la integración del menor en la familia de acogida y los vínculos afectivos con la familia de origen (que se eliminan sistemáticamente como consecuencia del acogimiento) nunca procederá el retorno a la familia biológica. BALLESTEROS DE LOS RÍOS, M., «Comentario a la STS 31 de julio de 2009», CCJC, vol. 84, 2010, p. 1457-59; BENAVENTE, P., «Riesgo, desamparo y acogimiento de menores», cit., p. 42; ORDÁS ALONSO, M., «El nuevo sistema de protección de menores en situación de riesgo o desamparo como consecuencia de la entrada en vigor de la Ley 26/2015 de julio», Aranzadi civil-mercantil. Revista doctrinal, vol. 9, 2016, p. 42.

29 Téngase en cuenta que con anterioridad a la reforma de 2015 se hacía referencia a la conveniencia de mantener al menor en su familia de origen únicamente en el art. 11, apartado 2 de la LOPJM, al enumerar los criterios que debían regir la actuación de los poderes públicos. Y se hacía referencia a esta circunstancia en la letra $\mathrm{b}$ del art.11.2 tras establecerse en primer lugar, en la letra a), que los poderes públicos debían regirse por la supremacía del interés del menor. Además, el art. $172 \mathrm{CC}$-ahora modificado- decía en su párrafo 4: «Se buscará el interés del menor y se procurará, cuando no sea contrario a su interés, su reinserción en su propia familia...» En la actualidad el art. 172.ter.2, CC ya no dice que se procurará la reinserción, sino que 
La doctrina sentada en esta sentencia ha sido utilizada con frecuencia por sentencias posteriore ${ }^{30}$ para confirmar la situación de acogimiento en que se encuentra el menor [en supuestos en muchos casos discutibles, vid. por ej. SSTS de 9 de julio 2015 (RJ 2015/2562); 15 de octubre de 2015 (RJ 2015/4861); 2 de diciembre2015 (RJ 2016/117)] y rechazar el retorno a la familia biológica ${ }^{31}$. Estas sentencias vienen a contraponer, como si se tratara de criterios enfrentados o antagónicos el interés del menor y la reinserción en su familia de origen y plantean, asimismo, la situación, como un conflicto entre los derechos de los padres biológicos y el interés del menor ${ }^{32}$.

se priorizará, lo que pone de manifiesto la relevancia que se otorga, y que se consagra en el citado art. 2.2 LOPJM, al mantenimiento de los vínculos familiares.

30 No puede dejar de señalarse que alguna STS, pese a tomar como base la citada resolución, la interpreta de forma más matizada y favorable al retorno del menor a su familia de origen. Así ocurre en la de STS 21 de noviembre de 2011 (RJ 2011/2362), que dice que el art. 172.4 CC «considera incluido en el interés del menor su reinserción en su propia familia cuando ello no sea contrario a su interés» (FJ 4. ${ }^{\circ}$ ) y la STS de 14 de noviembre 2011 (RJ 2012/3390), que confirma la sentencia recurrida, que había ordenado la recuperación de la patria potestad suspendida, aduciendo que los criterios utilizados por dicha resolución no eran contrarios al interés de las menores.

31 La STS de 9 de julio de 2015 (RJ 2015/2562) se refiere a un supuesto en que los padres de una menor se oponen a la declaración de desamparo acordada pocos días después de su nacimiento. El desamparo se había declarado sobre la base de que existían conflictos en la pareja que padecía (parece que ambos) una minusvalía psíquica, carecían de ingresos estables y tenían otros tres hijos bajo tutela de la Administración. En primera instancia y apelación se había desestimado la oposición. El TS confirma la sentencia recurrida y reitera la doctrina de la sentencia de 31 julio 2009, en particular el párrafo transcrito en la nota anterior (FJ. $3^{\circ}$ ). En la sentencia de 15 de octubre 2015 (RJ 2015/4861) un menor fue apartado de sus padres debido a que la madre padecía una enfermedad mental que le había llevado en dos ocasiones a estar ingresada en una unidad mental. El padre no parece que presentara ningún problema, pero la Administración había adoptado previamente medidas de protección respecto de otros cuatro hijos (de hecho, una de esas medidas dio lugar a la STEDH de 18 de junio de 2013, que condenó a España por vulnerar el art. 8 de la Convención). La oposición de los padres fue desestimada en primera instancia y en apelación. La SAP, siguiendo la doctrina del TS ya mencionada, se basó en la superior jerarquía que el legislador atribuía al deber de perseguir el interés del menor frente a la reinserción familiar. El TS, pese a que en ningún momento se había contemplado la posibilidad de que el padre (que trabajaba y pasaba largas temporadas en Francia) se hiciera cargo de la menor, afirma, con base en la sentencia de 9 de julio de 2009, que la resolución recurrida no se aparta del interés del menor. La sentencia de 2 de diciembre de 2015 (RJ 2016/117) versa sobre un procedimiento de oposición al acogimiento preadoptivo de un menor declarado en desamparo. La AP, que entendía que no había razones para separar al menor de la madre, rumana y con graves problemas económicos que la llevaban a desplazarse en busca de trabajo, había considerado improcedente el acogimiento. El TS, sin embargo, niega el retorno a la familia de origen basándose en la STS de 31 de julio 2009.

32 Se refiere a ello la citada STS de 31 de julio de 2009, que indica que «el derecho de los padres biológicos no es reconocido como principio absoluto... y tampoco tiene carácter de derecho o interés preponderante, sino de fin subordinado al fin al que debe atenderse de forma preferente, que es el interés del menor... Las medidas que deben adoptarse respecto del menor son las que resulten más favorables para el desarrollo físico intelectivo e integración social del menor contemplando el posible retorno a la familia natural siempre que sea compatible con las medidas más favorables al interés del menor»». Utiliza esta misma argumentación la STS de 15 de octubre de 2015 (RJ 2015/4861), mencionada en la nota anterior, en su FJ 3. ${ }^{\circ}$, apartado 3. Asimismo, la STS de 2 de diciembre de 2015 (RJ 2016/117), que ordena el mantenimiento del acogimiento preadoptivo (que había dejado sin efecto por la sentencia recurrida) y afirma que ante «el interés de los menores debe ceder el de la madre biológica». 
La STS de 17 de marzo de 2016 (RJ 2016/1132), por su parte, confirma la sentencia recurrida, que rechazó que el menor continuara teniendo relación con su familia ${ }^{33}$ aduciendo que el interés del menor tiene superior jerarquía frente a la posible reinserción en la familia biológica. Esta sentencia cita en su argumentación los nuevos arts. 11.2 y 19 bis de la LOPJM $^{34}$, indicando que sirven de guía para interpretar el interés del menor en situaciones anteriores a la reforma; pero, sin embargo, omite toda referencia al nuevo art. 2 LOPJM $^{35}$. De haberse tenido en cuenta este precepto, creo que la solución no podría ser la misma, pues de dicho artículo se deduce claramente que el retorno a la familia de origen o el mantenimiento de relaciones con ella no debe considerarse como un principio opuesto al del interés del menor y supeditado a este; sino, por el contrario, como el mejor modo de conseguir o proteger ese interés, salvo que puedan ponerse en peligro otros valores fundamentales que integran ese interés y deban considerarse prioritarios ${ }^{36}$.

33 Esta sentencia se refiere a una demanda de oposición a la resolución de acogimiento preadoptivo de un menor que se encontraba en un centro tutelado junto con otro hermano. La madre y la abuela del menor solicitaron que se mantuviera a este en el centro, permitiéndole seguir en contacto con una y otra y, en especial, con su hermano, del que no debía ser separado.

34 El art. 11.2 LOPJM no ha sido modificado tras la reforma de 2015 y sigue estableciendo, como criterios a tener en cuenta por los poderes públicos, pero en apartados independientes, la supremacía del interés superior del menor y «el mantenimiento en su familia de origen, salvo que no sea conveniente para su interés». Por su parte, el art. 19 bis, que parece recoger la doctrina de la repetida sentencia de 31 de julio de 2009, exige, para acordar el retorno del menor desamparado a su familia de origen, además de la evolución positiva de la misma «que se hayan mantenido los vínculos, que concurra el propósito de desempeñar las responsabilidades parentales adecuadamente y que se constate que el retorno con ella no supone riesgos relevantes para el menor a través del correspondiente informe técnico. En los casos de acogimiento familiar, deberá ponderarse, en la toma de decisión sobre el retorno, el tiempo transcurrido y la integración en la familia de acogida y su entorno, así como el desarrollo de vínculos afectivos con la misma».

Puede verse la crítica a este último precepto de ORDÁS ALONSO, M., «El nuevo sistema de protección de menores en situación de riesgo o desamparo como consecuencia de la entrada en vigor de la Ley 26/2015 de julio», cit., p. 42, que pone de manifiesto la imposibilidad de que concurran los requisitos exigidos, máxime cuando por lo general se priva a los padres biológicos de visitar a sus hijos o comunicarse con ellos.

35 También, curiosamente, la STS de 2 de diciembre de 2015, ya mencionada, cita el nuevo art. 19 bis LOPJM, que se refiere a los requisitos para el retorno del menor a su familia, omitiendo toda referencia al nuevo art. 2 LOPJM.

36 Hay que llamar la atención, además, sobre el hecho de que en el caso resuelto por esta sentencia no se estaba discutiendo sobre el retorno del menor a su familia, que es a lo que se refiere el art.19 bis LOPJM, sino, simplemente, sobre la no separación de los hermanos, que era la consecuencia del acogimiento acordado, y el mantenimiento de los vínculos con la familia de origen. De hecho, el propio Ministerio Fiscal, aunque se opuso a la estimación del recurso de casación, solicitó que se favoreciera la relación entre los hermanos. Sin embargo, el TS, pese a reconocer la razonabilidad de tal petición elude decidir sobre tal extremo indicando que la petición «no había sido objeto de debate con la singularidad necesaria» debiendo por tanto plantearse ex novo los posibles legitimados». Sorprende también esta excusa, puramente formal, cuando en la propia sentencia se había indicado previamente que la jurisprudencia constitucional (STC de 10 de diciembre de 1984) ha admitido la existencia de menor rigor formal en los procesos relativos a menores «admitiendo que las medidas que les afecten se fijen en interés de ellos, incluso con independencia de lo pedido por las partes en litigio» (FJ 2 ${ }^{\circ}$, apartado 2, párrafo final). Por lo que lo lógico hubiese sido que se aceptara tal petición.

Una postura más proclive al mantenimiento del menor en su familia ofrece la STS de 2 de octubre de 2017 (RJ 2017/4274), aunque, para justificar la devolución de menor a su progenitora no cita el art. 2.2 LOPJM 
En este sentido, tras la modificación del art. 2 LOPJM, hay que entender que la permanencia en la familia de origen $-\mathrm{y}$, por consiguiente, la reinserción familiar en caso de previa separación ordenada administrativamente- así como el mantenimiento de los lazos familiares, no es una circunstancia externa o ajena al interés del menor, que debe ser tomada en consideración solo cuando no se oponga a dicho interés. Es, por el contrario, un elemento integrante de su mejor interés y, por consiguiente, un objetivo a perseguir cuando se adopta una medida de protección del menor ${ }^{37}$. En segundo lugar; debe evitarse plantear la reintegración familiar como un derecho de los padres que entra en conflicto con el interés del menor ${ }^{38}$, pues se trata en realidad de un derecho del hijo, que debe ser respetado si se busca su mejor interés, y que solo debería ser desconocido cuando existan evidencias fundadas de que el retorno a su familia puede perjudicarle ${ }^{39}$.

La importancia de mantener al menor en el seno de su propia familia se refleja ahora en la nueva regulación de la situación de riesgo $\mathrm{o}^{40}$, dirigida a adoptar medidas que permitan evitar el posible perjuicio para el menor pero manteniéndole en el núcleo familiar. Hasta ahora la doctrina venía criticando la tendencia de la Administración a actuar precipitada-

sino el art. 1b.2 (sic.) LO1/96 que establece como principio rector de la actuación de los poderes públicos en relación con los niños «el mantenimiento del menor en el medio familiar de origen salvo que no sea conveniente para su interés».

37 Es, como indica ORDÁS ALONSO, M., «El nuevo sistema de protección de menores en situación de riesgo o desamparo como consecuencia de la entrada en vigor de la Ley 26/2015 de julio», cit., p. 40, la directriz que debe guiar las medidas de protección del menor. Así se desprende, por otra parte, de la jurisprudencia del TEDH que ha señalado en numerosas ocasiones que el art. 8 de la Convención implica el derecho para un progenitor de que se adopten medidas capaces de reunirle con su hijo, indicando que la asunción de la tutela administrativa de un niño debe considerarse una medida temporal a suspender tan pronto como la situación se preste, de modo que cualquier acto de ejecución debe ser coherente con un objetivo final: unir de nuevo al progenitor natural y al niño (entre otras: STEDH de 18 junio de2013 caso R.M.S. contra España, ap. 81 y 89; sentencia de 7 de agosto de 1996, caso Johansen contra Noruega, ap. 78; S. 25 febrero 1992, caso Margareta y Roger Andersson contra Suecia, ap. 91; sentencia de 22 junio de 1989 caso Eriksson contra Suecia, ap. 71).

38 Señala ORDÁS ALONSO, M. «El nuevo sistema de protección de menores en situación de riesgo o desamparo como consecuencia de la entrada en vigor de la Ley 26/2015 de julio», cit., p. 43 que es un error «considerar que el principio de reintegración familiar es un derecho de los padres cuando, en igual o mayor medida, es también un derecho del hijo».

39 Como indica ORDÁS ALONSO, M., «El nuevo sistema de protección de menores en situación de riesgo o desamparo como consecuencia de la entrada en vigor de la Ley 26/2015 de julio», cit., p. 45 «el interés del menor no consiste en procurar "encontrarle" el mejor núcleo familiar posible sino en "su mantenimiento en el núcleo familiar de pertenencia por razón de nacimiento, que es el naturalmente llamado a proporcionar los mayores lazos afectivos y donde naturalmente ha de desarrollarse con mayor potencialidad su personalidad"».

40 Con anterioridad a la reforma la ley simplemente mencionaba la situación de riesgo (que, sin embargo, había sido regulada en algunas CCAA como Cataluña). Ahora existe una completa regulación en el art. 17 LOPJM. Del art. 17.2 LOPJM se deduce que en primer lugar debe intentarse reparar la situación de posible perjuicio para el menor en el seno de la propia familia y solo si los progenitores no colaboran en la ejecución de las medidas adoptadas (proyecto de intervención social y educativo familiar, art. 17.4) se declarará la situación de riesgo del menor (art. 17.5). En este caso la Administración Pública, emitirá una resolución administrativa que incluirá las medidas tendentes a corregir la situación de riesgo del menor (art. 17.6). Solo si las medidas adoptadas no provocan cambios en la situación que garanticen «que el menor cuenta con la necesaria asistencia moral o material», deberá valorarse la procedencia de declarar la situación de desamparo (art. 17.8). 
mente y acordar el desamparo en situaciones de mero riesgo, separando indebidamente a los hijos de sus padres ${ }^{41}$. Con la regulación actual es de esperar que se modifique esa situación y la Administración asuma que solo excepcionalmente y con carácter subsidiario deben adoptarse medidas, como la declaración de desamparo, que impliquen la separación del menor de sus progenitores ${ }^{42}$. Sin embargo, aunque esta y otras modificaciones, como la incorporada en el art. art. 18.2 párrafo $2^{\circ} \mathrm{LOPJM}^{43}$, o las referencias al carácter temporal de los distintos tipos de guarda (v.gr. art. 172 bis 1; art. 173 bis 1, b) ${ }^{44}$, están en consonancia con el principio según el cual lo más beneficioso para el menor es permanecer en su familia, no ocurre lo mismo si se atiende a la regulación del retorno del menor. Aunque el objetivo de cualquier medida de protección debiera ser garantizar la reunificación familiar, lo cierto es que el art. 19 bis LOPJM no facilita la reunificación. Dicho precepto exige, para que proceda el retorno del menor desamparado a su familia de origen, requisitos similares a los recogidos en la STS de 31 de julio de 2009, que la doctrina criticaba por considerarlo de difícil cumplimiento ${ }^{45}$. En concreto, el citado precepto exige que se hayan mantenido los

41 La doctrina pone de relieve cómo en la práctica es frecuente que la Administración adopte resoluciones de
desamparo cuando lo que existe es una mera situación de riesgo, que no debería llevar a separar al menor de su
familia. Los tribunales las amparan bajo el argumento de la protección del interés superior del menor, pero una
vez puesta en marcha la maquinaria de la Administración, el paso del tiempo y la pérdida de vínculos con los
familiares convierte en irreversible la situación. BENAVENTE MOREDA, P., «Riesgo, desamparo y acogimiento
de menores. Actuación de la Administración e intereses en juego», cit., pp. 31, 41. ORDÁS ALONSO, M., «El
nuevo sistema de protección de menores en situación de riesgo o desamparo como consecuencia de la entrada en vigor de la Ley 26/2015 de julio», cit., pp. 7, 8, 18.

42 Inciden en la subsidiariedad y excepcionalidad de las medidas que entrañen la separación del menor de su familia de origen, GARCÍA GARNICA, M.C., «La guarda como medida de protección de menores y personas con discapacidad tras su reforma por la Ley 21/2014 de 28 de julio, de modificación del sistema de protección a la infancia y a la adolescencia», $A D C$, vol. 70, núm. 4, 2017, p. 1411; PÉREZ ÁLVAREZ, M.A., «Consideraciones sobre la evolución del sistema de protección de menores», en MAYOR DEL HOYO, M.V. (dir.), El nuevo régimen jurídico del menor, Cizur Menor (Thomson-Aranzadi), 2017, pp. 103, 106; MÚRTULA LAFUENTE, V., «El interés del menor en las situaciones de riesgo y desamparo provocadas por la violencia de género», en MAYOR DEL HOYO, M.V. (dir.), El nuevo régimen jurídico del menor, Cizur Menor (Thomson-Aranzadi), 2017. p. 157. También DÍEZ GARCÍA, H., "Comentario al art. 172 CC», en BERCOVITZ RODRÍGUEZ-CANO, R. (dir.), Las modificaciones al Código civil del año 2015, Valencia (Tirant lo Blanch), 2016, pp. 499-503, quien indica que el art. 172 CC debe ser interpretado a la luz de lo establecido en el art. 2.2 LOPJM.

43 Este precepto dispone que la situación de pobreza de los progenitores no podrá ser tenida en cuenta para la valoración de la situación de desamparo, no pudiendo separarse a un menor de sus progenitores por el mero hecho de que uno u otros padezcan una discapacidad. Dicha prohibición es importante, porque en muchos casos la ausencia de recursos económicos o la inestabilidad emocional de los progenitores han sido la causa determinante de que se les haya privado de sus hijos. Vid. ORDÁS ALONSO, M., «El nuevo sistema de protección de menores en situación de riesgo o desamparo como consecuencia de la entrada en vigor de la Ley 26/2015 de julio», cit., pp. 8-10.

44 GARCÍA GARNICA, M.C., «La guarda como medida de protección de menores y personas con discapacidad tras su reforma por la Ley $21 / 2014$ de 28 de julio, de modificación del sistema de protección a la infancia y a la adolescencia», cit., p. 1412.

45 GUILARTE MARTÍN-CALERO, C., «La configuración del interés del menor ex art. 2 LOPJM y su posible aplicación a la determinación del interés de la persona con discapacidad intelectual o mental: una 
vínculos familiares y ordena tener en cuenta el transcurso del tiempo. El problema es que, aunque la ley consagra el derecho del menor a relacionarse con sus progenitores, hermanos y parientes, durante las medidas de protección (art. 21 bis 1.d LOPJM ${ }^{46}$, otorga a la Administración la facultad de regular del régimen de visitas y comunicaciones de los menores con sus parientes, con posibilidad de suspenderlo si lo considera necesario en interés del menor, lo que deberá ser notificado al MF (art. $161 \mathrm{CC}$ ). Y si se suprimen las visitas es evidente que se dificulta la reintegración familiar que, es en principio, el objetivo a buscar, generándose un círculo vicioso en el que se justifica la imposibilidad de devolver al menor a su familia de origen, aunque haya habido una evolución favorable, ante la falta de contacto del menor con sus progenitores acordada por la propia Administración ${ }^{47}$. Tampoco facilita la reinserción familiar el plazo de dos años previsto en el art. 172.2 CC para que la familia pueda solicitar la revocación de desamparo porque ello implica que, transcurridos esos dos años, la situación se convertirá en irreversible con independencia de cómo haya evolucionado la familia ${ }^{48}$

Lo indicado pone de manifiesto, en definitiva, una cierta contradicción interna en la regulación, pues si lo más beneficioso para el menor es la permanencia en su familia de origen, que es además la más apta para que pueda preservarse la identidad cultural, religiosa, etc., del menor, debería facilitarse el retorno a su familia, cuando previamente ha sido necesaria la separación. En este punto creo que sería importante interpretar el art. 19 LOPJM a la luz de los criterios enunciados en el art. 2.2 LOPJM no perdiendo de vista que solo en casos excepcionales, en los que la familia de origen no haya evolucionado correctamente, debería rechazarse la reintegración.

propuesta», cit., p. 500; BALLESTEROS DE LOS RÍOS, M., «Comentario a la STS 31 de julio de 2009», cit., pp. 1457-59.

46 Es de notar que el derecho a relacionarse con los familiares se reconoce ahora en el art. $160 \mathrm{CC}$ como un derecho del menor, mientras que en la anterior redacción de dicho precepto se contemplaba como un derecho del progenitor, «los progenitores, aunque no ejerzan la patria potestad, tienen el derecho de relacionarse con sus hijos menores...». RUIZ-RICO RUIZ-MORÓN, J., «Últimas reformas de las instituciones privadas de protección de menores y la filiación por la Ley 26/2015, de modificación del sistema de protección a la infancia y la adolescencia», Revista Doctrinal Aranzadi civil-mercantil, vol. 3, 2015, pp. 7, 8

47 La doctrina critica, por ello, que se atribuya tal facultad a la Administración, indicándose que la resolución debería ser ratificada por el juez y, como mínimo, por el Ministerio Fiscal, vid. ORDÁS ALONSO, M., «El nuevo sistema de protección de menores en situación de riesgo o desamparo como consecuencia de la entrada en vigor de la Ley 26/2015 de julio», cit., p. 31; BELUCHE RINCÓN, «Reflexiones sobre el acogimiento de menores tras la Ley 26/2014 de julio de modificación del Sistema de Protección de la infancia y la adolescencia», en MORALES MORENO, A.M. (dir.), Estudios jurídicos. Liber Amicorum en honor a Jorge Caffarena, Madrid (Centro de Estudios Registrales), 2017, p. 102.

48 ORDÁS ALONSO, M., «El nuevo sistema de protección de menores en situación de riesgo o desamparo como consecuencia de la entrada en vigor de la Ley 26/2015 de julio», cit., p. 36. La situación se agrava si se tiene en cuenta que, como señala MÚRTULA LAFUENTE, $\mathrm{V}$., «El interés del menor en las situaciones de riesgo y desamparo provocadas por la violencia de género», cit., p. 166, el art. 177.2.3 CC no exige ahora el asentimiento de los progenitores para la adopción del hijo una vez transcurridos esos dos años. 


\section{Los criterios b y c y la prestación del consentimiento al tratamiento médico}

Los criterios b) y d) del art. 2.2 LOPJM reflejan una postura subjetiva a la hora de valorar en qué consiste el interés del menor. Tales criterios tienen especial relevancia cuando un tercero, habitualmente los padres o representantes de un menor, debe adoptar una decisión en el ámbito de los derechos de la personalidad de este, por carecer el menor de la madurez necesaria para adoptarla por sí mismo. De acuerdo con el art. 154.2 CC, que ordena tener en cuenta la personalidad del menor ${ }^{49}$, los citados criterios de determinación del interés del menor, y lo establecido en el art. 9, sobre el derecho del menor a ser oído y escuchado, parece evidente que para adoptar la decisión más conforme con el interés del menor no puede prescindirse de los deseos, opiniones, identidad sexual, convicciones culturales, religiosas o de otro tipo de este. Ahora bien, cabe preguntarse qué peso ha de darse en la práctica a esos deseos o convicciones. Una de las hipótesis más habituales en las que un tercero puede tener que adoptar una decisión en lugar del menor es la relativa a la prestación del consentimiento médico, y a ello voy a referirme a continuación.

A. La prestación del consentimiento al tratamiento médico por menores de edad tras la reforma de 2015

La ley 26/2015 ha modificado el art. 9 de la Ley 41/2002 restringiendo la capacidad de los menores para adoptar decisiones de carácter médico. Con anterioridad a la reforma, el citado art. 9 de la Ley 41/2002 reconocía a los menores de edad la posibilidad de dar el consentimiento al tratamiento médico si tenían al efecto suficiente capacidad natural, presuponiéndoseles tal capacidad a partir de los 16 años $^{50}$. Así, el art. 9.3.c) disponía que cuando se trata de «menores emancipados o mayores de 16 años no cabe prestar el consentimiento por representación». El nuevo art. 9.4 mantiene esa premisa, pero a continuación dispone que, no obstante, «cuando se trate de una actuación de grave riesgo para la vida o salud del menor, según el criterio del facultativo (art. 9.4 segundo inciso), el consentimiento deben prestarlo los representantes del menor». La contradicción como puede observarse es palpable, pues el precepto viene a decir al mismo tiempo que el menor mayor de 16 años tiene y no tiene capacidad.

Lo que subyace a esta modificación legislativa es en realidad el temor a que el menor rechace un tratamiento vital, posibilidad esta que había suscitado muchos reparos en la doctrina $^{51}$ y en el propio Ministerio Fiscal, que en su Circular 1/2012, propugnaba la irrelevancia

49 Recuérdese que el art. 154.2 CC dispone que la patria potestad debe ejercerse en interés de los hijos y de acuerdo con su personalidad, y el último inciso de dicho precepto añade que «si los hijos tuvieren suficiente madurez deberán ser oídos siempre antes de adoptar decisiones que les afecten». Las mismas reglas han de aplicarse, como es lógico, a los menores sujetos a tutela, aunque el art. 216, que se refiere a la tutela con carácter general, solo indique que las funciones tutelares deben ejercerse «en beneficio del tutelado».

50 Por todos vid. SANTOS MORÓN, M.J., «Menores y derechos de la personalidad», cit., pp. 80, 81.

51 Buena parte de la doctrina negaba, no solo la posibilidad de que el menor de 16 años, pero con suficiente madurez, rechazara un tratamiento médicamente indicado contra la voluntad de sus padres (y obviamente la de 
de la voluntad del menor cuando su sentido sea contrario a la indicación médica y comporte un riesgo vital para aquél ${ }^{52}$. En mi opinión, si de lo que se trata es de privar al menor de la posibilidad de rechazar un tratamiento vital, porque se entiende que el Estado debe proteger a toda costa la vida del sujeto menor de edad, habría sido más honesto decirlo con claridad. $\mathrm{O}$, al menos, podría haberse redactado el precepto de manera más coherente pues, si se afirma que el menor tiene capacidad para decidir no puede afirmarse lo contrario a continuación. Lo lógico, en todo caso, habría sido establecer que el menor emancipado o mayor de 16 años puede otorgar el consentimiento en caso de actuaciones que, a juicio del facultativo, no sean de grave riesgo para la vida o salud del menor, si bien en caso contrario, el consentimiento deberá prestarlo el representante legal. En realidad, hasta ahora se venía entendiendo que para valorar la capacidad necesaria para otorgar el consentimiento informado ha de tenerse en cuenta el balance riesgo-beneficio del tratamiento, y en particular, el beneficio terapéutico que de él puede derivar en relación con la entidad de la lesión y el riesgo para la salud o la vida del paciente que pueda ocasionar. De ahí que sea lógico concluir que para adoptar decisiones complejas y que impliquen graves riesgos es precisa una mayor madure $z^{53}$.

los médicos), sino también la posibilidad de que el menor mayor de 16 años, al que la ley le atribuía claramente la capacidad para otorgar el consentimiento informado, rechazara un tratamiento vital. La propia redacción del art. 9.3. c) Ley 41/2002 generaba además cierta confusión pues, tras disponer que tratándose de menores emancipados o con 16 años no cabía prestar el consentimiento por representación, indicaba que «en caso de actuación de grave riesgo» debía informarse a los padres, cuya opinión debía ser tenida en cuenta para la toma de la decisión. Esta regla resultaba de difícil interpretación pues, si el menor tenía suficiente capacidad para decidir por sí mismo, no se comprendía cuál era el papel que jugaba la opinión de los padres en la toma de la decisión. Algunos autores, entendían, por ello, que dicha regla permitía interpretar que, cuando el menor rechazaba un tratamiento vital, debía informarse a los padres, debiendo en su caso, decidir el juez ex art. 158 CC (vid. el estado de la cuestión en SANTOS MORÓN, M.J., «Menores y derechos de la personalidad», cit., pp. 83-87; ASENSIO SÁNCHEZ, M.A., Patria potestad, minoría de edad y derecho a la salud, Madrid (Dykinson), 2012 pp. $108 \mathrm{y}$ ss. Más recientemente, RIVERA ÁLVAREZ, J.M., «El consentimiento informado del adolescente en situaciones de grave riesgo: ¿Autonomía privada vs. interés superior del menor?», $R D P$, vol. 2, 2015, pp. 78 y ss. Entre los autores que manifiestan reparos a aceptar el rechazo al tratamiento por parte de un menor puede verse: DOPICO GÓMEZ-ALLER, J., «Problemas del consentimiento informado por representación», en Consentimiento por representación, Barcelona (Fundación Victor Grífols i Lucas), 2010, pp. 75-77; MORENO ANTÓN, M., «La libertad religiosa del menor de edad en el contexto sanitario» cit., p. 114; OJEDA RIVERO, R., «El rechazo del tratamiento médico por los menores de edad en grave riesgo», InDret, vol. 3, 2015, p. 13.

52 En esta Circular de la Fiscalía General del Estado sobre «el tratamiento sustantivo y procesal de los conflictos ante transfusiones de sangre y otras intervenciones médicas sobre menores de edad en caso de riesgo grave», se mantiene que la voluntad del menor, cuando su sentido sea contrario a una indicación médica, debe considerarse siempre irrelevante (p. 24). Además, se sugiere que cuando el menor maduro se niegue a una intervención médica grave y sus representantes legales estén a favor de esta, prevalecerá su opinión sobre la del menor, si bien, si la situación no es urgente, es preferible que decida el Juez (p. 27).

53 SANTOS MORÓN, M.J., «Menores y derechos de la personalidad», cit., pp. 68, 81; asimismo SANTOS MORÓN, M.J., Incapacitados y derechos de la personalidad. Tratamientos médicos, honor, intimidad e imagen, cit., p.77; ASENSIO SÁNCHEZ, A., Patria potestad, minoría de edad y derecho a la salud, cit., p. 105; RIVERA ÁLVAREZ, J. M., «El consentimiento informado del adolescente en situaciones de grave riesgo: ¿Autonomía privada vs. interés superior del menor?», cit., p. 76; NEVADO CATALÁN, V., «El interés superior del menor maduro en situación de grave riesgo: entre la autonomía del paciente y el derecho a la vida», $A D C$, vol. 70, núm. 4, 2017, pp. 1556, 1557. 
Ahora bien, hasta la reforma de 2015 cabía entender que a partir de los 16 años se tenía suficiente capacidad para adoptar todo tipo de decisiones médicas. Del nuevo art. 9.4 se deduce, sin embargo, que el menor mayor de 16 años solo tiene capacidad para consentir tratamientos que no conlleven graves riesgos. Es decir, la redacción actual del precepto implica que, siempre que se esté ante un tratamiento o intervención que suponga un grado importante de riesgo (lo que han de valorar los facultativos ${ }^{54}$ ), deberán dar el consentimiento los representantes legales, si bien una vez oída y tenida en cuenta la «opinión» del menor.

Por lo que respecta a los menores de edad inferior a 16 años, del art. 9.3.c) a sensu contrario se desprende, al igual que con anterioridad, que el menor puede tener capacidad para consentir, cuestión que debe valorar el facultativo atendiendo a la madurez del menor y el tipo de actuación médica de que se trate. Ahora bien, si a los menores emancipados o mayores de 16 años solo se les reconoce capacidad para otorgar el consentimiento informado cuando el tratamiento médico no conlleva grave riesgo para su vida o salud, es evidente que los menores de 16 años, estarán en igual situación. Dado que la determinación de cuándo se está ante una situación de grave riesgo queda a juicio del facultativo es posible que, para evitar problemas, se acabe reconociendo capacidad al menor, aunque sea mayor de 16 años y/o cuente con suficiente madurez, solo para consentir intervenciones banales y de escasa entidad.

En cualquier caso, cuando el menor, de edad inferior a 16 años, no esté capacitado para adoptar la decisión, dispone el art. 9.3.c) Ley 41/2002 que el consentimiento lo dará el representante legal del menor después de haber escuchado su opinión conforme a lo dispuesto en el artículo 9 de la LOPJM. Conviene destacar que la remisión al art. 9 supone que no solo deberá escucharse al menor mayor de 12 años (que era lo que establecía con anterioridad dicho precepto $)^{55}$ sino también al menor de edad inferior «si tiene capacidad para comprender y evaluar el asunto concreto a tratar» ${ }^{56}$.

54 Como es fácil colegir, el problema, en la práctica, va a residir en la determinación de los tratamientos que suponen un «grave riesgo». ¿Lo supone todo tratamiento quirúrgico - pensemos en las posibles consecuencias de la anestesia-? ¿Sólo los de especial complejidad?

55 Con anterioridad a la reforma de la Ley 41/2002 por la Ley 26/2015, a tenor del art. 9.3.c) cabía distinguir tres hipótesis: a) menor emancipado o de más de 16 años, en cuyo caso, en principio, el consentimiento debía prestarlo el menor; b) menor de entre 12 y 16 años, en cuyo caso debía comprobarse si el menor tenía suficiente capacidad, pero, aun no teniéndola, debía tenerse en cuenta su opinión; c) menor de edad inferior a 12 años, que presumiblemente sería considerado incapaz para consentir. SANTOS MORÓN, M.J., «Menores y derechos de la personalidad», cit., p. 81 . Tras la reforma de 2015 hay quien sigue manteniendo estas tres hipótesis, así lo hace, por ej. RAVETLLAT BALLESTÉ, I., «El consentimiento informado de la persona menor de edad a los tratamientos e intervenciones médicas», La Ley, Derecho de Familia, vol. 13, 2017, pp. 5 y ss., pero debe tenerse en cuenta que ha de escucharse, no solo al menor mayor de 12 años, sino también al de edad inferior si las circunstancias lo permiten (véase la nota siguiente) y que en realidad la situación del menor mayor de 16 años y el de edad inferior no es muy diferente porque tanto en un caso como en otro solo podrán consentir tratamientos que no conlleven «graves riesgos» a juicio del facultativo.

56 En este sentido RAVETLLAT BALLESTÉ, I., «El consentimiento informado de la persona menor de edad a los tratamientos e intervenciones médicas», cit., p. 6. Conviene señalar que el art. 9.1 dice que el menor deberá ser oído y escuchado «sin discriminación alguna por edad» «teniéndose debidamente en cuenta sus opiniones en función de su edad y madurez». Y el art. 9.2 que considera en todo caso maduro al menor mayor 
Partiendo de las premisas enunciadas, en aquellos casos en que, a juicio del facultativo, el menor -ya sea mayor de 16 años, ya de edad inferior-no tiene capacidad para otorgar el consentimiento a la intervención, sus padres deben adoptar la decisión que corresponda teniendo en cuenta su mejor interés. Ahora bien, para valorarlo han de tomar en consideración sus deseos, su opinión y convicciones (art. 2 LOPJM), que ha de poder expresar en todo caso si tiene más de 12 años, pero también, dependiendo de su capacidad para comprender y evaluar la situación, si tiene una edad inferior (art. 9.2).

¿En qué medida están vinculados los padres por las opiniones del menor? Como es lógico, el peso que ha de darse a la opinión del menor debe ser mayor en función de su edad y madurez (art. 2. 2.b LOPJM), y en particular cuando está emancipado o tiene más de 16 años ${ }^{57}$, pero parece que en ningún caso podrá ser de relevancia si es contraria a la intervención y esta es necesaria para su vida o su salud. Así se deduce del propio art. 9.6 que dice que, cuando el consentimiento se otorgue por representación, «la decisión deberá adoptarse atendiendo siempre al mayor beneficio para la vida o salud del paciente» ${ }^{58}$, ordenando acudir a la autoridad judicial cuando la decisión sea contraria a «dichos intereses». Asimismo, el art. 17.10 LOPJM dispone que «la negativa de los progenitores, tutores, guardadores o acogedores a prestar el consentimiento respecto de los tratamientos médicos necesarios para salvaguardar la vida o integridad física o psíquica de un menor constituye una situación de riesgo», en cuyo caso las autoridades sanitarias deberán poner en conocimiento de la autoridad judicial los hechos en cuestión. Dado que las normas mencionadas no hacen ninguna excepción, hay que entender que incluso en el supuesto en que la negativa de los progenitores, tutores, etc., sea conforme con la opinión del propio menor, y se base en los deseos, la identidad o las convicciones culturales o religiosas del mismo, procede

de 12 años, dispone previamente que «la madurez habrá de valorarse por personal especializado, teniendo en cuenta tanto el desarrollo evolutivo del menor como su capacidad para comprender y evaluar el asunto concreto a tratar en cada caso». Por consiguiente, aunque el menor mayor de 12 años debe ser oído siempre, esto no implica que los menores de edad inferior no tengan igual derecho. Lo tendrán, siempre que, a juicio de personal especializado, tengan suficiente capacidad para comprender y evaluar el asunto de que se trate.

57 Compárese la redacción del art. 9.4 inciso segundo, que dice que los representantes del menor emancipado o mayor de 16 años deben decidir «una vez oída y tenida en cuenta la opinión del mismo», con la del art. 9.3.c), que, para el resto de supuestos, solo dice que deberá ser escuchada la opinión del menor.

58 De aquí cabe deducir que los representantes legales solo pueden someter al menor a intervenciones que estén terapéuticamente indicadas y redunden en beneficio de la vida o la salud del paciente. Con anterioridad a la reforma la doctrina ha venido entendiendo, en este sentido, que los representantes del menor no pueden dar el consentimiento a una intervención de cirugía estética a menos que sea claramente necesaria desde el punto de vista psicológico para el menor: DE LAMA AYMÁ, A., La protección de los derechos de la personalidad del menor, cit., pp. 323, 324; SANTOS MORÓN, M.J., «Menores y derechos de la personalidad», cit., p. 83, nota 65; ASENSIO SÁNCHEZ, A., Patria potestad, minoría de edad y derecho a la salud, cit., p. 126. Sin embargo, el Decreto 49/2009 de la Junta de Andalucía, aunque exige un examen psicológico del menor, permite a sus representantes otorgar el consentimiento a operaciones de cirugía estética (arts. 5 y 6). Siendo la Ley 41/2002 una ley básica y, con base en lo establecido actualmente en el art. 9.6 cabe dudar de que sea admisible la regulación andaluza y los representantes de un menor puedan dar su consentimiento a una intervención de cirugía estética a menos que se trate de cirugía plástica o reconstructiva y sea necesaria para el equilibro mental del menor. 
derivar la cuestión a la autoridad judicial. Es decir, no parece que los deseos y opiniones del menor, sus convicciones religiosas o su identidad cultural puedan tener mucho peso en la decisión de sus representantes si conducen a una decisión que pone en riesgo la salud o la vida del menor.

Resulta, por consiguiente, que el legislador en la reforma de 2015 ha apostado decididamente por hacer prevalecer la vida y la salud del menor frente a su derecho a la autodeterminación personal o su derecho a la libertad religiosa, pese a que, de acuerdo con los criterios introducidos en el art. 2 LOPJ, deberían ser respetados para alcanzar su mejor interés ${ }^{59}$. A lo dicho podría objetarse que el Estado debe garantizar que cuando son los representantes del menor quienes deciden en su lugar, actúen siempre en beneficio de lo que es objetivamente su interés. Sin embargo, cabe preguntarse si la preservación de la vida del menor es siempre lo más beneficioso para él.

Para resolver la cuestión de si es aceptable la decisión de un menor de edad, incluso mayor de 16 años, de rechazar un tratamiento vital, la doctrina sugiere que han de tener en cuenta las razones esgrimidas por el menor. Si el rechazo está justificado por razones neutralmente válidas - esto es, razones que cualquiera puede racionalmente comprender analizando la situación desde la perspectiva y en las circunstancias en que se encuentra el menor (v.gr. eliminación del sufrimiento)-, deberá respetarse su voluntad ${ }^{60} 61$.

59 Vid. NEVADO CATALÁN, V., «El interés superior del menor maduro en situación de grave riesgo: entre la autonomía del paciente y el derecho a la vida», cit., p. 1566, quien concluye diciendo (p. 1571) que la regulación actual supone «una vuelta al paternalismo tradicional en contra de la progresiva evolución en materia de derechos y autonomía del paciente que se venía observando». Por su parte, RIVERA ÁLVAREZ, J. M., «El consentimiento informado del adolescente en situaciones de grave riesgo» cit., p. 85, señalaba, en relación con el Proyecto de Ley de Modificación del Sistema de Protección a la Infancia y la Adolescencia, y la posible modificación del art. 9 Ley 41/2002, que la solución adoptada, suponía «la total objetivación de la decisión a adoptar y la elusión, en este caso, de los deseos e intereses del menor. Esto supone alejar nuestro sistema legal del principio de autonomía configurado en el Convenio sobre Derechos del niño (1989) y adscribirnos más a la tradición del paternalismo médico como solución del conflicto entre autonomía y salud».

60 OJEDA RIVERO, R., «El rechazo del tratamiento médico por los menores de edad en grave riesgo», cit., pp. 22 y ss., señala que

«el rechazo al tratamiento por parte de un menor en grave riesgo no puede ser analizado sin tener en cuenta las razones que lo han llevado a adoptar tal decisión», y estima que deben respetarse «sus decisiones cuando se basen en razones válidas desde una perspectiva imparcial y moralmente neutral» (pp. 29, 30). Para evaluar la validez de las razones del menor recurre al concepto de «objetividad posicional» según el cual «determinados juicios son objetivamente correctos en el sentido de que cualquier persona en la misma situación que quien los emite llegaría, tras considerar de forma detenida y racional todos los aspectos relevantes de la misma, a su misma conclusión», cit., p. 23.

${ }^{6}$ Se pone como ejemplo el caso de Hannah Jones, una niña británica de 13 años, que desde los cinco había estado en tratamiento para su leucemia y que rechazó un trasplante de corazón porque se sentía incapaz de soportar el sufrimiento aparejado. Los médicos finalmente aceptaron su opinión y renunciaron a realizar el trasplante, si bien tras cumplir 14 años posterioridad cambio de opinión y se sometió a la operación. Vid. OJEDA RIVERO, R., «El rechazo del tratamiento médico por los menores de edad en grave riesgo», cit., pp. 24-26, 30. NEVADO CATALÁN, V. «El interés superior del menor maduro en situación de grave riesgo: entre la autonomía del paciente y el derecho a la vida», cit., p. 1563, 1564. 
Sin embargo, la postura mantenida por el legislador parece que obligaría, en todo caso, a decantarse por la imposición del tratamiento contra la voluntad del menor y cualesquiera que sean sus razones para oponerse al mismo. Es decir, aunque en línea de principio la consecución del interés del menor exige respetar sus opiniones y convicciones culturales o religiosas (art. 2.2, b y d LOPJM), lo cierto es que la propia ley desatiende esas consideraciones cuando puede estar en riesgo la vida o la salud del menor.

En realidad, la misma dicotomía se plantea cuando se trata de menores que, no solo no tienen madurez para decidir, sino tampoco para expresar sus opiniones, como sucede en caso de menores de corta edad o con alguna discapacidad que les impide manifestar su voluntad. En este caso parece claro que los padres han de adoptar la decisión que sea necesaria para preservar la vida y la salud del menor.

Pensemos, sin embargo, en la siguiente hipótesis: menor gravemente enfermo y sin pronóstico de posible mejoría que es o debe ser mantenido con vida de manera artificial. Los médicos consideran que lo que redunda en su interés es la supresión (o no aplicación) del tratamiento médico para evitar la prolongación del sufrimiento. ¿Sería aceptable legalmente el consentimiento de los progenitores? Cabe pensar que si hay consenso entre estos y los médicos el asunto se mantendrá en el ámbito privado. Pero si no lo están deberá decidir el juez. En tal caso ¿podrá este suscribir el criterio médico o hay que entender que está vinculado por lo establecido en el art. 9.6 Ley 41/2002 que ordena atender «siempre al mayor beneficio para la vida o la salud del paciente», y debe por tanto ordenar la aplicación o continuación del tratamiento?

En España no parece que se haya planteado un caso de estas características, pero son varios los suscitados en el Derecho inglés. En Reino Unido hay una consolidada doctrina jurisprudencial sobre este tipo de situaciones, que en cierto modo explica la reciente, y polémica, decisión del caso Alfie Evans ${ }^{62}$, que llevó a sus padres a recurrir, aunque sin éxito al TEDH ${ }^{63}$. Como regla, si el menor carece de capacidad para decidir (si no supera el

62 Vid., entre otras noticias: <https://elpais.com/internacional/2018/04/24/actualidad/1524589613_252635>, $<$ https://www.abc.es/sociedad/abci-quien-alfie-evans-201804182059_noticia.html $>$. [Consultado el 13/09/2018].

63 El TEDH, con fecha 23 de abril de 2018 rechazó la solicitud de recurso presentada por los padres sobre la base de la violación del art. 5 de la Convención europea de Derechos Humanos, al igual que previamente había rechazado otra solicitud basada en la vulneración de los art. 14 y 8 de la Convención (puede verse la nota de prensa en: $<$ https://www.echr.coe.int/sites/search_eng/pages/search.aspx\#\{\%22fulltext $\% 22:[\% 22$ Evans\%20 v.\%20United\%20Kingdom\%22]>. [Consultado el 01/01/2019]. En un caso anterior (Auto de 26 de junio de 2017, caso Gard y otros contra Reino Unido, Tol 6.409.431), el TEDH consideró inadmisible el recurso presentado por los padres de un menor (Charlie Gard) que padecía una rara enfermedad y era mantenido artificialmente con vida, contra la decisión médica, avalada por los tribunales ingleses, de retirar el tratamiento artificial, impidiéndole someter al menor a un tratamiento experimental en EEUU. El TEDH estimó que no se vulneraba el art. 2 de la Convención, que consagra el derecho a la vida, por considerar que tanto en lo relativo a la retirada de tratamientos artificiales como en lo relativo al uso de tratamientos experimentales los Estados tienen un cierto margen de apreciación, y en este caso las sentencias emitidas por los tribunales ingleses en las distintas instancias estaban meticulosa y adecuadamente razonadas. (Puede verse el comentario a esta sentencia de 
denominado «Gillick Test»), en Derecho inglés corresponde a los padres otorgar el consentimiento al tratamiento médico. En la práctica se tiende a buscar una decisión consensuada entre los médicos y los padres del menor ${ }^{64}$, pero los supuestos de discordancia han de ser resueltos por el Juez, que debe decidir atendiendo al mejor interés del menor ${ }^{65}$. Y, a la hora de concretar qué debe entenderse por interés del menor en estos casos, los tribunales ingleses estiman que, si bien existe una fuerte presunción a favor de mantener con vida al menor, esa presunción no es irrefutable, ya que el «best interests» abarca no solo conceptos médicos, sino también emocionales, relacionados con el bienestar, y en particular, la ausencia de sufrimiento. Así, si se demuestra que la vida del niño puede llegar a ser intolerable o una especie de muerte en vida, cabría considerar destruida dicha presunción ${ }^{66}$. Como base de esta doctrina suele citarse una resolución de 1990, dictada en el caso In Re J (A Minor) (Wardship: Medical Treatment) 1990 Oct 15 [1990] 3:930-45, relativa a un niño nacido a las 27 semanas de gestación que padecía daño cerebral, convulsiones y cuadriplegia espástica, y respecto del cual los médicos opinaban que, en caso de sufrir paro respiratorio, no debía ser ventilado mecánicamente. El niño estaba bajo la guarda de la Administración y el oficial solicitor se negaba a aceptar la no ventilación. De ahí que los médicos solicitaran una autorización judicial que les fue concedida ${ }^{67}$.

Uno de los ejemplos más conocidos de esta postura, por su repercusión en la prensa, es el de Charlotte Wyatt -Re Wyatt (a Child) (Medical Treatments: Parents consent) 2004 EWHC 2247- una niña que había nacido a las 26 semanas de gestación y sufrido una infección al nacer, lo que ocasionó que tanto su respiración como sus funciones cerebrales

MARÍN CASTÁN, M.J. «La polémica decisión del TEDH sobre el caso Gard y otros contra el Reino Unido», Revista de Bioética y Derecho, vol. 43, 2018, pp. 262 y ss). A similares conclusiones ha llegado el TEDH en los casos Afiri and Biddarri contra Francia (23 de enero de 2018) y Haastrup contra Reino Unido (6 de marzo de 2018), en la que ha considerado que las decisiones de los tribunales internos de retirar el tratamiento artificial dirigido a mantener con vida a los menores (en el primer caso una menor de 14 años en estado vegetativo; en el segundo un menor de un año que desde su nacimiento precisaba ventilación artificial) no vulneran el art. 2 de la Convención. Vid. HENDRICKS, A.C. «End-of-life decisions. Recent jurisprudence of the European Court of Human Rights», Era Forum, septiembre, 2018.

64 Sobre ello BIRCHLEY, G., «Deciding Together? Best interests and Shared Decision-Making in Paediatric Intensive Care», Health Care Anal, vol. 22, 2014, pp. 204, 205.

65 BRIDGEMAN, J., «A response to Death and best interests», Clinical Ethics, vol. 4, 2009, p. 15.

${ }_{66}$ En esta resolución de un lado, se intenta aplicar la doctrina del «substitute judgement» al preguntarse el juez si, en caso de que el menor hubiese tenido madurez y juicio para decidir, habría considerado la vida tolerable. Por otra parte, se indica que para valorar el mejor interés del menor hay que tener en cuenta el sufrimiento y la calidad de vida que el menor podría experimentar si su vida se prolonga, al mismo tiempo que el sufrimiento que conlleva el tratamiento en sí mismo. CHIH HONG, M.J., «Medical Treatments for Children- Who decides when doctors and parents disagree?», Leeds Journal of Law and Criminilogy, vol. 1, núm. 1, 2013, p. 35; BATHIA, N., Critically impaired infants and end of life decision making, Londres-Nueva York (Routledge), 2015, p. 40.

67 CHIH HONG, M.J., «Medical Treatments for Children- Who decides when doctors and parents disagree?», cit, p. 34; BRIDGEMAN, J., «A response to death and best interests», cit., p. 192, observa que el estándar a tener en cuenta parece ser que, para que la vida sea digna de ser vivida, debe ser tolerable y no implicar un sufrimiento absoluto. 
quedaran sumamente deterioradas. El daño era irreparable, se creía que estaba ciega, sorda e incapaz de movimiento voluntario, aunque la evidencia sugería que padecía dolor. Se discutía si, en caso de que dejara de respirar, debía ser ventilada artificialmente, lo que requeriría una traqueotomía y le generaría gran sufrimiento sin posibilidad de prolongar su vida significativamente. Los médicos consideraban que no debía aplicársele respiración artificial, mientras que los padres opinaban lo contrario. El hospital solicitó por ello autorización judicial para no aplicarle respiración mecánica en caso de que sufriera un fallo respiratorio. La autorización les fue concedida para un periodo de 6 meses. Transcurrido el mismo los padres, aduciendo que el estado de la menor había mejorado, solicitaron una nueva decisión. El juez, sin embargo, mantuvo la misma opinión. En esta resolución el juez se basó en el caso anteriormente mencionado, In Re J, y concluyó que, dada la situación de la menor y los riesgos y sufrimientos que conllevaba la traqueotomía, la aplicación del tratamiento no podía considerarse en su interés ${ }^{68}$.

Existen diversos casos similares, en los que, en caso de menores gravemente enfermos y sin posibilidad de recuperación, los jueces han ordenado la retirada o no puesta en práctica de tratamientos dirigidos a prolongar su vida por entender que ello solo puede provocar mayor sufrimiento al menor sin obtener a cambio ningún placer ${ }^{69}$. Hay que reconocer que las

68 BRAZIER, M., «An intractable Dispute: When Parents and Professionals disagree», Medical Law Review, vol. 13, 2005, pp. 412-417; BATHIA, N., Critically impaired infants, cit., p. 47 y ss.

69 Otras decisiones que, de acuerdo con la doctrina enunciada, ordenan retirar el tratamiento necesario para prolongar la vida del menor son las siguientes: $\operatorname{Re} C$ (a minor) 199740 BMLR 31 (Fam div). Una menor de 15 meses padecía atrofia muscular espinal y estaba conectada a un respirador. Su cerebro estaba irremediablemente dañado. Los médicos consideraban en su mejor interés desconectarla del ventilador y, en caso en que no pudiera respirar, no proceder a la reventilación. Los padres estaban de acuerdo en desconectarla para comprobar si podía respirar por sí sola pero no en que no fuese reventilada en caso negativo. El Juzgado consideró que la decisión médica era en mejor interés de la menor a fin de evitarle más sufrimiento.

Re J (A minor) Wardship: Medical Treatment (1999). Un niño prematuro hubo de ser resucitado varias veces. Tenía daño cerebral y se creía que iba a desarrollar parálisis, ceguera y sordera. Aunque no había discordancia entre padres y médicos, se solicitó una orden judicial para que el menor no fuese tratado ni resucitado en caso de necesidad. El tribunal la otorgó, entendiendo que ello sólo aumentaría su sufrimiento sin claro beneficio para el menor.

NHS Trust vs OT (2009). Un bebé tenía un raro desorden metabólico y sufría daño cerebral y problemas respiratorios. Estaba siendo alimentado por tubo nasogástrico porque no podía tragar y necesitaba respiración artificial. Los padres acudieron a los tribunales para evitar que los médicos retiraran el tratamiento al menor. La jueza consideró que el menor tenía un mínimo grado de conciencia, pero parecía sentir dolor y que continuar el tratamiento era inútil y sólo podía incrementar el sufrimiento. Los padres intentaron recurrir la resolución, pero la Corte de apelación no admitió el recurso.

Re Baby RB (A child) 2009 EWHC 3269 (Fam). Un bebé sufría un raro desorden genético y síndrome de miastenia congénita. Estaba gravemente discapacitado y era alimentado artificialmente al igual que respiraba por medios artificiales. A los 13 meses los médicos consideraron que debía suprimirse la ventilación y permitir al menor morir. La madre aceptó la decisión, pero no el padre, por lo que fue necesaria una orden judicial. El juez consideró que la supresión de la ventilación era la solución que redundaba en interés del menor.

Re KH (a child) 2012 EWHC 318 (Fam). En este supuesto, se partía de la base de que los padres del menor, que estaba bajo la guarda de la Administración, carecían de capacidad para consentir, si bien fueron consultados por el tribunal. El menor, de tres años, había sufrido encefalitis a los pocos meses lo que le había provocado un 
decisiones mencionadas suponen un juicio de valor acerca de cuándo la vida es «tolerable» o no lo es, pero ello es difícilmente evitable ${ }^{70}$. Y lo que reflejan los casos mencionados es que es discutible que la vida (su mero mantenimiento) deba considerarse siempre lo que redunda en el mejor interés del menor.

Frente a ello, el texto legal que analizamos parece que obliga a pronunciarse siempre, ya sea a los representantes legales, ya sea al juez, por el mantenimiento de la vida del menor. La única posibilidad que, quizás, pueda permitir flexibilizar este planteamiento es el recurso al apartado 7 del art. 9 Ley 41/2002, que dispone que «la prestación del consentimiento por representación será adecuada a las circunstancias y proporcionada a las necesidades que haya que atender, siempre a favor del paciente y con respeto a su dignidad personal $\rangle^{71}$. Aunque este precepto se refiere a los representantes del menor, creo que puede ser igualmente aplicado cuando es el juez quien, en caso de conflicto, debe decidir en aras de su mejor interés. De acuerdo con esta regla, quizás podría concluirse que mantener con vida a un menor en circunstancias como las expresadas es desproporcionado y lesivo para su dignidad. Pero esta posible solución, como es previsible, no estará exenta de controversia.

\section{B. La modificación de la regulación del aborto de las menores de edad}

Relacionada con la cuestión del consentimiento informado del menor de edad, está la relativa al consentimiento al aborto. La LO 11/2015, ha suprimido el n. ${ }^{\circ} 4$ del art. 13 de la LO 2/2010, que reconocía a las menores mayores de 16 años capacidad para consentir la interrupción voluntaria del embarazo ${ }^{72}$, limitando su capacidad ${ }^{73}$. Dicha ley ha introducido

grave deterioro cerebral, además de padecer distonia, escoliosis, dificultad visual, incapacidad para comunicarse, y necesitar ser alimentado artificialmente. El hospital en el que llevaba ingresado un año solicitó la aprobación judicial de un plan de tratamiento en el que proponía que, si la condición del menor empeoraba, no sería sometido a tratamientos agresivos para mantenerlo con vida (concretamente ventilación artificial o resucitación en caso de paro cardiaco). El tribunal, sobre la base de que un eventual tratamiento solo prolongaría su vida sin mejorar su calidad, aumentando posiblemente su sufrimiento sin que pudiera experimentar ningún placer, consideró que dicho tratamiento no podía considerarse en su mejor interés.

Vid. BRIDGEMAN, J., «A response to death and best interests», cit., p. 192; BATHIA, N., Critically impaired infants and end of life decision making, cit., pp. 41, 45, 47; CHIH HONG, M. J., «Medical Treatments for Children- Who decides when doctors and parents disagree?», cit. p. 35; BRAZIER, M., «An intractable Dispute: When Parents and Professionals disagree», cit., p. 444.

70 Además, cabe plantearse el riesgo de que la decisión médica pueda estar influida en parte por la escasez de recursos disponibles.

71 Este precepto ha sido, por ej., invocado por la doctrina para negar que, cuando se trata de enfermos terminales con graves padecimientos físicos, sus representantes legales puedan imponer la prolongación de la situación. DOPICO GÓMEZ-ALLER, J., «Problemas del consentimiento informado por representación», cit., pp. 60-70.

72 La EM, punto I, lo justifica en la necesidad de que las menores se encuentren acompañadas por sus representantes legales en un trance de tanta importancia e impacto futuro, y a fin de facilitar a los representantes el cumplimiento de los deberes derivados de la patria potestad y la tutela.

73 El art. 13.4 de la LO 2/2010 reconocía a las menores mayores de 16 años capacidad para consentir, pero incluía un segundo apartado que generó bastante desconcierto en cuanto disponía que debía informarse 
un nuevo apartado en el art. 9.5 de la Ley 41/2002 que dispone: «[p]ara la interrupción voluntaria del embarazo de menores de edad o personas con capacidad modificada judicialmente será preciso, además de su manifestación de voluntad, el consentimiento expreso de sus representantes legales. En este caso, los conflictos que surjan en cuanto a la prestación del consentimiento por parte de los representantes legales se resolverán de conformidad con lo dispuesto en el Código Civil».

Por consiguiente, a diferencia de lo que sucedía con anterioridad a la reforma, en la actualidad para llevar a cabo el aborto no basta el consentimiento de la menor, aunque tenga capacidad natural o sea mayor de 16 años. Se exige en todo caso el consentimiento de los representantes de la menor, además de su «manifestación de voluntad», lo que puede dar lugar a conflictos porque es posible que la menor y sus representantes sean de distinto parecer. La remisión que realiza el art. 9.5 Ley 41/2002 al CC, para resolver los conflictos que surjan no resulta de utilidad, porque no hay en el CC ningún precepto específico destinado a regular los conflictos de este tipo. Por ello entiendo que la eventual discordancia deberá resolverla el juez, por la vía del art. $158.6 \mathrm{CC}$, que le permite adoptar las medidas necesarias para apartar al menor «de un peligro o evitarle perjuicios en su entorno familiar» ${ }^{74}$.

En segundo lugar, cabe preguntarse qué se entiende por «manifestación de voluntad» del menor ${ }^{75}$. En mi opinión, dado que la interrupción voluntaria del embarazo es una intervención médica más, una mínima coherencia sistemática exige interpretar esta expresión a la luz de las reglas generales en materia de consentimiento informado. Si los menores mayores de 16 años o con edad inferior pero con suficiente madurez pueden dar el consentimiento

al menos a uno de los representantes legales de la menor. Antes de la LO 2/2010 el art. 9.4 Ley $41 / 2002$ se remitía, en cuanto a la interrupción voluntaria del embarazo, «a lo establecido con carácter general sobre la mayoría de edad»-esta referencia fue suprimida por la citada LO 2/2010-. No obstante, dado que ningún precepto exigía la mayoría de edad para someterse al aborto, se consideraban aplicables las reglas generales, y en concreto, el art. 162 CC en relación con el art. 9.3 c) Ley 41/2002, entendiéndose, por consiguiente, que la menor con capacidad natural, y en todo caso mayor de 16 años, podía dar el consentimiento al aborto. DOPICO GÓMEZ-ALLER, J., «Problemas del consentimiento informado por representación», cit., pp. 80 y ss.; SANTOS MORÓN, M.J., «Menores y derechos de la personalidad», cit., p. 87-89.

${ }_{74}$ Entre los posibles preceptos aplicables, el art. 156 CC se refiere a los desacuerdos entre los progenitores, con lo que no operaría en este caso. El art. 163 sí se refiere a la hipótesis en que los padres tienen un «interés opuesto» al de los hijos (en ese caso se nombra un defensor judicial) y a la misma situación, pero para el supuesto de tutela, se refiere el art. 299 CC. En mi opinión, estos preceptos están pensados para conflictos de intereses de otra naturaleza, previos a la situación en que debe decidir el representante en sustitución del menor y que pueden inclinarle a tomar una decisión no favorable al menor (v. gr. padre e hijo son herederos del mismo causante). En el caso analizado se está, en cambio, ante un supuesto de diversidad de opinión, por lo que la vía más plausible, como se indica en el texto, parece la del art. 158 CC que legitima tanto al «hijo» como «a cualquier pariente» para solicitar al juez la adopción de medidas en beneficio del menor.

75 LACASTA GOÑI, M., «La validez del consentimiento otorgado por las menores de edad a la hora de someterse a la intervención voluntaria del embarazo: Una crítica a la LO 11/2014 desde una perspectiva penalista», RJUAM, vol. 34, núm. 2, 2016, p. 175, observa que el precepto podría interpretarse entendiendo que la manifestación de voluntad de la menor equivale al consentimiento, o bien que es una especie de «asentimiento» similar a la declaración que han de dar en el procedimiento de adopción personas que, sin formar parte de la relación adoptiva, como el cónyuge del adoptante, se verán afectadas. 
a las intervenciones médicas que no implican graves riesgos (art. 9.4 en relación con art. 9.3.c Ley 41/2002), debe entenderse (salvo que se estime que la interrupción voluntaria del embarazo conlleva graves riesgos, cosa que en principio parece descartable) que tratándose de menores de tales características es preciso su consentimiento ${ }^{76}$ junto con el de sus progenitores o representantes. Cuando la menor tiene menos de 16 años y además carece de la suficiente madurez, conforme a la regla general corresponde otorgar el consentimiento a sus representantes, habiendo escuchado la opinión de la menor de acuerdo con el art. 9 LOPJM. Sin embargo, dado que la interrupción del embarazo conlleva consecuencias que van más allá de la preservación de la salud física o psíquica de la mujer y están en íntima conexión con su derecho al libre desarrollo de la personalidad, la norma especial exige algo más. No basta con que los padres o representantes recaben la opinión de la menor, sino que es necesario que ella manifieste su voluntad, entiendo que ante el equipo médico.

En realidad, la necesidad de que la menor emita su voluntad sobre el aborto, parece que va a operar fundamentalmente a modo de derecho de veto en los casos en que la menor es contraria al aborto y sus representantes son proclives al mismo (salvo en el caso de aborto terapéutico al que me referiré después). Dado que cuando la menor desea el aborto no basta su consentimiento, podría argüirse que en la modificación legislativa subyace un planteamiento ideológico claramente favorable al mantenimiento del embarazo ${ }^{77}$.

Sin embargo, aunque posiblemente exista tal planteamiento ideológico, creo que en realidad esta postura es coherente con la propia configuración de la interrupción del embarazo como un derecho de la mujer que, en ejercicio de su libertad personal, puede decidir si quiere o no ser madre. Desde este punto de vista, si la gestante quiere continuar el embarazo, imponerle la interrupción contra su voluntad, cuando no es necesario para su vida o

76 Ha de advertirse que el RD 825/2010 de desarrollo parcial de la LO 2/2010 exige, en su art. 8, además del consentimiento de las menores de 16 y 17 años, que se acredite el cumplimiento del requisito de información del apartado 4 del art. 13 de la LO 2/2010. Este requisito hacía referencia a la necesidad de informar a los representantes legales de la menor pese a corresponder a ella la prestación del consentimiento, pero dicho apartado 4 del art. 13 está derogado. Sin embargo, dado que ahora se exige el consentimiento de los representantes además del de la menor, parece que tanto una como otros deberán ser, igualmente, receptores de la información relativa a la interrupción del embarazo.

77 LACASTA GOÑI, M., «La validez del consentimiento otorgado por las menores de edad a la hora de someterse a la intervención voluntaria del embarazo: Una crítica a la LO 11/2014 desde una perspectiva penalista» cit., p. 179, dice, en este sentido, que la LO 11/2014 muestra una clara predilección por la protección de la expectativa de vida del feto ya que «el consentimiento de la menor ningún complemento ni bendición necesita cuando esta decide continuar con el embarazo, mientras que si desea interrumpirlo requiere obligatoriamente el consentimiento expreso de quienes ejercen su patria potestad». También sugiere un cierto sesgo GONZÁLEZ AGUDELOS, G., «Consecuencias jurídicas y político-criminales de la elevación de la edad del consentimiento sexual en los derechos sexuales y de salud sexual y reproductiva del menor de edad», Revista Electrónica de Ciencia Penal y Criminología, vol. 18, 2016, pp. 21, 22, que considera paradójico que no se considere a una menor capaz de decidir por sí misma sobre la interrupción del embarazo, pero sí se la considere madura para proseguir el embarazo y cuidar al menor o eventualmente darlo en adopción. 
su salud, puede constituir un atentado contra su libertad personal ${ }^{78}$. No obstante, conviene distinguir diversas situaciones:

a) En los casos de interrupción del embarazo necesaria para la vida o la salud de la menor dentro de las veintidós semanas de gestación (art. 15. a Ley 2/2010), la voluntad en contra de esta puede considerarse irrelevante. La solución aquí sería la misma que en el caso de rechazo, por parte de un menor o de sus representantes, de un tratamiento vital para su vida o su salud. Si tanto los padres como la menor se negaran al aborto podrían los facultativos acudir a la autoridad judicial con base en el art. 9.6 Ley 41/2002.

b) Cuando se trata de aborto «libre» con base en la solicitud de la gestante, dentro de las primeras 14 semanas (art. 14 Ley10/2010), me parece difícilmente admisible, conforme a lo indicado con anterioridad, que pueda imponerse el aborto contra la voluntad de la menor, en particular cuando tiene más de 16 años y posee suficiente madurez. En caso contrario, si se trata, por ej. de una menor de corta edad (v.gr. 13 años) cabría quizás argumentar que, pese a que la admisibilidad del aborto está ligada en este caso a la mera voluntad de la mujer, pueden existir razones «objetivas» que justifiquen la necesidad de dicha intervención, en contra de su voluntad, en aras de su mejor interés. Así, cabe plantearse la posibilidad de que los progenitores recurran al juez por la vía del art. 158.6 CC aduciendo que la prolongación del embarazo puede suponer un claro perjuicio para el desarrollo futuro de la menor y va a impedir la satisfacción de sus necesidades físicas, materiales, educativas, etc. (criterio art. 2,2, letra a) LOPJM). Pese a todo, la eventual autorización del juez a favor del aborto exigiría sopesar muy cuidadosamente los posibles beneficios y perjuicios para la menor y tener la seguridad de que la interrupción del embarazo contra su voluntad (que puede estar basada en sus propias convicciones ideológicas o religiosas, criterio art. 2,2, letra d) LOPJM) no va a causarle ningún trauma ni secuela psicológica.

c) En caso de riesgo de graves anomalías del feto, que permite llevar a cabo el aborto dentro de las 22 semanas de gestación (art. 15.b Ley 2/2010) entiendo que la situación es similar a la descrita con anterioridad. Si la menor es mayor de 16 años o tiene suficiente madurez no cabe imponerle el aborto contra su voluntad. Si la menor carece de la suficiente madurez, cabría, por parte de los representantes, el

78 Los autores que defienden la consideración del aborto como un derecho de la mujer suelen entender que el obligar a una menor a continuar con su embarazo hasta el parto, contra su voluntad, constituye un acto de violencia inadmisible DOPICO GÓMEZ-ALLER, J., «Problemas del consentimiento informado por representación», cit., p. 98; LACASTA GOÑI, M., «La validez del consentimiento otorgado por las menores de edad a la hora de someterse a la intervención voluntaria del embarazo: Una crítica a la LO 11/2014 desde una perspectiva penalista», cit., p. 179. Aun compartiendo esa opinión, entiendo, sin embargo, que el mismo argumento funciona en sentido inverso, e igual acto de violencia puede darse cuando se impone el aborto contra la voluntad de la menor. 
recurso a la autoridad judicial. Ahora bien, aunque en esta hipótesis parece evidente que el nacimiento de un niño con deficiencias psíquicas o físicas tendría una grave incidencia en la vida futura de la madre, también ha de tenerse en cuenta que la decisión de los representantes legales puede estar motivada por su propio interés y no exclusivamente el de la menor ${ }^{79}$.

Planteemos ahora la situación inversa. Esto es, aquella en que la menor desea la interrupción del embarazo y sus padres o representantes se oponen.

a) En el supuesto de aborto terapéutico la solución es clara. Los padres no pueden oponerse a una intervención necesaria para la vida o la salud de la menor. Si lo hacen los médicos podrán solicitar la correspondiente autorización judicial (art. 9.6 Ley 41/2002).

b) Si el aborto no está terapéuticamente indicado y se trata de aborto a solicitud de la embarazada dentro de las 14 primeras semanas de gestación, o bien de aborto basado en el riesgo de anomalías en el feto, creo que los representantes legales de la menor no pueden negarse a dar su consentimiento a la interrupción del embarazo a menos que existan razones que justifiquen claramente que la prolongación del embarazo es la solución más beneficiosa para la menor. Aquí hay que recordar que cualquier decisión de los representantes debe orientarse a la consecución del interés de la menor y que este interés debe prevalecer frente a sus posibles convicciones ideológicas o religiosas sobre el aborto (cfr. art. 2.4 inciso segundo LOPJM). A tal efecto los progenitores o representantes de la menor deben tener en cuenta los criterios del art. 2.2 LOPJM, sopesando en qué medida la prolongación del embarazo o su interrupción pueden incidir en el futuro desarrollo de esta y en la satisfacción de sus necesidades básicas, en particular, las «educativas, emocionales y afectivas» (art. 2.2 letra a) y además deberán tener en cuenta los deseos, sentimientos y opiniones de la menor, así como sus convicciones culturales, religiosas o de otro tipo (art. 2.2, letras b y d) puesto que es bastante dudoso que imponer el embarazo contra una clara oposición de la menor pueda redundar en su interés (del mismo modo que lo es, en mi opinión, imponerle el aborto en contra de su deseo de ser madre o sus convicciones ideológicas o religiosas).

En caso de que exista persistencia de la negativa a la práctica del aborto por parte de los representantes de la menor esta podría solicitar a la autoridad judicial, ex art. $158.6 \mathrm{CC}$ que autorice la interrupción del embarazo. La menor podría alegar que la continuación de

\footnotetext{
79 El art. 15 letra c) también permite el aborto, con posterioridad a las 22 semanas de gestación cuando se detecten anomalías fetales incompatibles con la vida y así conste en un dictamen emitido con anterioridad por un médico o médica especialista, distinto del que practique la intervención, o cuando se detecte en el feto una enfermedad extremadamente grave e incurable en el momento del diagnóstico y así lo confirme un comité clínico. En mi opinión, en esta última hipótesis, y si el feto es prácticamente inviable, no parece probable que la menor se oponga rotundamente al aborto querido por sus representantes. No, al menos, si se le informa adecuadamente de la situación.
} 
la gestación puede causarle perjuicios. Pero además, dado que la LO ha elevado el principio del interés superior del menor a la «categoría» de derecho ${ }^{80}$, podría posiblemente invocar la vulneración, por parte de sus representantes, de su derecho a que su interés superior sea considerado primordial en la toma de decisiones que le conciernen. Evidentemente el juez, a la hora de decidir, deberá sopesar todos los extremos anteriormente enunciados a fin de valorar si la interrupción del embarazo redunda en interés de la menor ${ }^{81}$.

\section{RECAPITULACIÓN}

El principio del interés del menor opera como guía o criterio rector en la toma de decisiones que le afectan, tanto si se trata de decisiones adoptadas por una autoridad administrativa o judicial, como si se trata de decisiones tomadas por los representantes del menor, en aquellos casos en que este carece de madurez para adoptarlas por sí mismo. Los criterios introducidos en el nuevo art. 2 LOPJM para facilitar la determinación del interés superior del menor en casos concretos, combinan aspectos objetivos (letras a y c) y subjetivos (letras b y d), pero dicho precepto no establece una jerarquía entre ellos limitándose a enumerar algunos elementos a tener en cuenta en la labor de ponderación de los mismos, que han de valorarse conforme a los principios de necesidad y proporcionalidad.

Para resolver el posible conflicto entre los criterios incluidos en el citado art. 2 LOPJM, ha de tenerse en cuenta: a) que la regla prevalente, según se deduce del conjunto de la regulación, es la protección del derecho a la vida del menor; b) que cuanto mayor sea el menor más relevancia ha de darse a sus deseos, opiniones y convicciones; y c) que cuando los representantes del menor adoptan decisiones relativas a sus derechos de la personalidad, por carecer el menor de suficiente madurez, es preciso respetar en la mayor medida posible sus deseos e inclinaciones.

Además, algunos de los criterios recogidos en el art. 2 LOPJM tienen mayor relevancia cuando se trata de decisiones de la autoridad administrativa o judicial, mientras que otros la tienen cuando se trata de decisiones adoptadas por los representantes del menor.

80 Así se indica en la EM, disponiendo el art. 2.1 LOPJM que «todo menor tiene derecho a que su interés superior sea valorado y considerado como primordial...»

81 No puede dejar de advertirse que el hecho de que el conflicto entre la postura de la menor y sus representantes deba ser resuelto por el juez conlleva un peligro claro: el transcurso de los plazos dentro de los que es admisible el aborto, en particular cuando se basa en el art. 14 LO 2/2010. Si, eventualmente, se llegara a la conclusión de que los representantes han actuado en contra del interés de la menor y esta, debido a la prolongación del conflicto, llega a verse imposibilitada para interrumpir el embarazo cabría plantearse, incluso, la posibilidad de que pudiera ejercitar, frente a sus representantes, una acción de responsabilidad por vulneración del art. 2 LOPJM. La eventual acción de responsabilidad, con todo, requeriría demostrar la culpa o negligencia paterna, y aquí la cuestión se torna compleja, porque ¿hasta qué punto la negativa de unos padres a consentir el aborto de la menor puede constituir un comportamiento «negligente» si se basa en sus propias convicciones morales o religiosas o en su propia concepción -puede que errónea- del «interés» de la menor? La interrogante, en cualquier caso, requiere un estudio independiente que excede del objeto de este trabajo. 
En concreto, el criterio relativo a la conveniencia de que la vida del menor se desarrolle en un entorno familiar adecuado, debiendo priorizarse la permanencia en su familia de origen y preservarse el mantenimiento de sus relaciones familiares (art. 2.2 letra c) es de especial interés en los casos de medidas administrativas de protección del menor. Hasta ahora, la impugnación de estas medidas, que conllevan habitualmente la separación del menor de su entorno familiar, ha generado cierta doctrina jurisprudencial que no facilita el retorno del menor a su familia de origen. La consagración legal del mencionado criterio debería dar lugar a una modificación de dicha doctrina jurisprudencial, que viene considerando la reinserción familiar como un objetivo contrapuesto al del interés del menor que debe ceder en aras de dicho interés. Del texto legal se desprende ahora, por el contrario, que lo prioritario debe ser la permanencia en la familia y, en caso de previa separación, la reinserción en ella. La reintegración familiar no es un derecho de los padres que entra en conflicto con el interés del menor, sino un derecho del hijo, que ha de ser respetado si se busca su mejor interés, y que solo en circunstancias excepcionales, en que existan indicios fundados de posible perjuicio para el menor, puede ser desconocido.

Los criterios contenidos en las letras b) y d) del art. 2.2 en cuya virtud en el proceso de valoración del interés el menor han de tenerse en cuenta sus deseos, sentimientos y opiniones, y preservarse su identidad cultural, religiosa, sexual, etc., son de especial relevancia en el ámbito de los derechos de la personalidad del menor, cuando sus representantes tienen que decidir en su lugar al carecer el menor de suficiente madurez para decidir por sí mismo (art. $162 \mathrm{CC}$ ). Parece evidente que, en este ámbito, para adoptar la decisión más conforme con el interés del menor no puede prescindirse de los deseos, opiniones, identidad, convicciones culturales, religiosas o de otro tipo de este. Lo cierto es, sin embargo, que, en la práctica, y cuando se trata de ciertos tipos de decisiones, la propia ley lleva a desatender los posibles deseos y convicciones del menor. Así sucede en el ámbito del consentimiento al tratamiento médico cuando está en juego la vida o salud del menor.

La reforma de 2015 ha restringido la capacidad de los menores para adoptar decisiones de carácter médico. El nuevo art. 9.4 Ley 41/2002 solo permite a los menores de edad -ya sean mayores de 16 años, ya sean de edad inferior pero con suficiente madurez-otorgar el consentimiento a intervenciones que no sean de grave riesgo para su vida o su salud. Cuando el consentimiento deben prestarlo sus representantes legales, estos han de escuchar la opinión del menor (en todo caso si tiene más de 12 años, pero también si es de edad inferior, en función de su capacidad de comprensión) y tomar en consideración sus deseos, opiniones y convicciones. Sin embargo, la ley no permite a los representantes del menor rechazar un tratamiento médico necesario para preservar su vida o su salud, aunque tal decisión sea lo más conforme con la opinión del menor y esté justificada por la particular situación en que este se encuentra. Tampoco parece que, en casos de menores que no pueden expresar su opinión, puedan los padres, o eventualmente la autoridad judicial, rechazar tratamientos vitales para el menor (art. 9.6 Ley 41/2002; 17.10 LOPJM). Y ello, aunque en el caso concreto quepa dudar de que la preservación de la vida del menor sea lo más beneficioso para 
él (a menos que pueda entenderse que tal decisión es contraria a la dignidad del menor, art. 9.7 Ley 41/2002).

Un caso particular de intervención médica, que cuenta con su propia regulación, es la interrupción voluntaria del embarazo. La LO 11/2015 ha limitado también la capacidad de las menores para consentir el aborto y exige en todo caso, además de su manifestación de voluntad, el consentimiento expreso de sus representantes legales. La manifestación de voluntad de la menor debe regirse por las mismas reglas que el consentimiento al tratamiento médico. Pero la necesidad añadida de consentimiento de los representantes puede dar lugar a conflictos si la menor y estos son de distinto parecer. Para solucionar los eventuales conflictos, y con independencia del posible recurso al art. 158.6 CC, hay que tener en cuenta que la decisión de los representantes debe estar guiada por el principio del interés de la menor. Como regla no cabe imponer el aborto contra la voluntad de la menor, salvo que la interrupción del embarazo sea necesaria para preservar la vida o la salud de esta. Si, por el contrario, los representantes se niegan a consentir el aborto deseado por la menor, y este tiene finalidad terapéutica, los médicos podrán solicitar autorización judicial para llevarlo a cabo. Cuando el aborto se basa en la mera voluntad de la menor o en la existencia de anomalías en el feto, y dado que para valorar el mejor interés de la menor han de tenerse en cuenta sus necesidades «educativas, emocionales y afectivas» (art. 2.2 letra a LOPJM), los deseos, sentimientos y opiniones de la menor, así como sus convicciones culturales, religiosas o de otro tipo (art 2.2, letras b y d LOPJM), la menor podrá recurrir al juez ex art. 158.6 CC en caso de que sus representantes no los tomen en consideración, ya que, de ser así, cabrá dudar de que la decisión de los representantes, contraria a la interrupción del embarazo, pueda considerarse adoptada «en su mejor interés».

\section{BIBLIOGRAFÍA}

ASENSIO SÁNCHEZ, A., Patria potestad, minoría de edad y derecho a la salud, Madrid (Dykinson), 2012.

BALLESTEROS DE LOS RÍOS, M., «Comentario a la STS 31 de julio de 2009», CCJC, vol. 84, 2010, pp. 1429-1459

BATHIA, N., Critically impaired infants and end of life decision making, LondresNueva York (Routledge), 2015.

BELUCHE RINCÓN, I., «Reflexiones sobre el acogimiento de menores tras la Ley 26/2014 de julio de modificación del Sistema de Protección de la Infancia y la Adolescencia», en MORALES MORENO. A. M., (dir.), Estudios jurídicos. Liber Amicorum en honor a Jorge Caffarena, Madrid (Centro de Estudios Registrales), 2017, pp. 93-112. 
BENAVENTE MOREDA, P., «Riesgo, desamparo y acogimiento de menores. Actuación de la Administración e intereses en juego», AFDUAM, vol. 15, 2011, pp. $15-62$.

BIRCHLEY, G., «Deciding Together? Best interests and Shared Decision-Making in Paediatric Intensive Care», Health Care Anal, vol. 22, 2014, pp. 203-222.

BRIDGEMAN, J., «A response to Death and best interests», Clinical Ethics, vol. 4, 2009, pp. 15-18.

BRAZIER, M., «An intractable Dispute: When Parents and Professionals disagree», Medical Law Review, vol. 13, 2005, pp. 412-418.

CHIH HONG, M.Y., «Medical Treatments for Children- Who decides when doctors and parents disagree?» Leeds Journal of Law and Criminilogy, vol. 1, núm. 1, 2013, pp. 31-44.

DE LAMA AYMÁ, A., La protección de los derechos de la personalidad del menor de edad, Valencia (Tirant lo Blanch), 2006.

DÍEZ GARCÍA, H. «Comentario al art. $172 \mathrm{CC}$, en BERCOVITZ RODRIGUEZCANO, R., (dir.), Las modificaciones al Código civil del año 2015, Valencia (Tirant lo Blanch), 2016, pp. 1781-1833.

DOPICO GÓMEZ-ALLER, J., «Problemas del consentimiento informado por representación», en Consentimiento por representación, Barcelona (Fundación Victor Grifols), 2010, pp. 38-99.

GARCÍA GARNÍCA, M.C., «La guarda como medida de protección de menores y personas con discapacidad tras su reforma por la Ley 21/2014 de 28 de julio, de modificación del sistema de protección a la infancia y a la adolescencia», $A D C$, vol. 7, núm. 4, 2017, pp. 1375-1421.

GONZÁLEZ AGUDELOS, G., «Consecuencias jurídicas y político-criminales de la elevación de la edad del consentimiento sexual en los derechos sexuales y de salud sexual y reproductiva del menor de edad», Revista Electrónica de Ciencia Penal y Criminología, vol. 18, 2016, pp. 1-31.

GUILARTE MARTÍN-CALERO, C., «La configuración del interés del menor ex art. 2 LOPJM y su posible aplicación a la determinación del interés de la persona con discapacidad intelectual o mental: una propuesta», en MAYOR DEL HOYO, M.V. (dir.), El nuevo régimen jurídico del Menor, Cizur Menor (Thomson-Aranzadi), 2017, pp. 485-518

GUILARTE MARTÍN-CALERO, C., «El interés superior del niño: La nueva configuración del art. 2 de la LO 15 de enero, de Protección Jurídica del Menor», en 
CABEDO MALLOL, V. y RAVETLLAT BALLESTÉ, I. (coords.), Comentario sobre las leyes de reforma del sistema de protección de la infancia y la adolescencia, Valencia (Tirant lo Blanch), 2016, pp. 87-128

HENDRICKS, A.C. «End-of-life decisions. Recent jurisprudence of the European Court of Human Rights», Era Forum, septiembre 2018, pp. 1-10

JONES P. y WELCH S., Rethinking Children's Rights, $2^{\mathrm{a}}$ ed., Londres-Nueva York (Bloomsbury), 2018.

HUETE NOGUERAS, J.J., «Desafíos de la nueva ley: derechos de los menores y papel del Ministerio Fiscal», en MAYOR DEL HOYO, M. V. (dir.), El nuevo régimen jurídico del menor, Cizur Menor (Thomson-Aranzadi), 2017, pp. 87-98.

LACASTA GOÑI, M., «La validez del consentimiento otorgado por las menores de edad a la hora de someterse a la intervención voluntaria del embarazo: Una crítica a la LO 11/2014 desde una perspectiva penalista», RJUAM, vol. 34, núm. 2, 2016, pp. 159-184.

MARÍN CASTÁN, M.J. «La polémica decisión del TEDH sobre el caso Gard y otros contra el Reino Unido», Revista de Bioética y Derecho, vol. 43, 2018, pp. 261-276.

MORENO ANTÓN, M., «La libertad religiosa del menor de edad en el contexto sanitario», AFDUAM, vol. 15, 2011, pp. 95-123.

MÚRTULA LAFUENTE, V., «El interés del menor en las situaciones de riesgo y desamparo provocadas por la violencia de género», en MAYOR DEL HOYO, M.V., El nuevo régimen jurídico del menor, Cizur Menor (Thomson-Aranzadi), 2017, pp. 149-168.

NAVAS NAVARRO, S., «El bienestar y el interés del menor desde una perspectiva comparada», en CABANILLAS SÁNCHEZ, A. (coord.), Estudios Jurídicos en Homenaje al profesor Díez-Picazo, t. I, Madrid (Civitas), 2003, pp. 689-713.

NEVADO CATALÁN, V., «El interés superior del menor maduro en situación de grave riesgo: entre la autonomía del paciente y el derecho a la vida», $A D C$, vol. 70, núm. 4, 2017, pp. 1543-1573.

NÚÑEZ ZORRILLA, M.C., «El interés superior del menor en las últimas reformas llevadas a cabo por el legislador estatal en el sistema de protección a la infancia y a la adolescencia», Persona y Derecho, vol. 73, núm. 2, 2015, pp. 117-160.

OJEDA RIVERO, R., «El rechazo del tratamiento médico por los menores de edad en grave riesgo», InDret, vol. 3, 2015.

ORDÁS ALONSO, M., «El nuevo sistema de protección de menores en situación de riesgo o desamparo como consecuencia de la entrada en vigor de la Ley 26/2015 
de julio», Aranzadi civil-mercantil. Revista doctrinal, vol. 9, 2016 (se ha utilizado la versión de Aranzadi Instituciones BIB 2016/80298).

PÉREZ ÁLVAREZ, M.A., «Consideraciones sobre la evolución del sistema de protección de menores», en MAYOR DEL HOYO, M.V. (dir.), El nuevo régimen jurídico del menor, Cizur Menor (Thomson-Aranzadi), 2017, pp. 99-114.

RAVETLLAT BALLESTÉ, I., «El consentimiento informado de la persona menor de edad a los tratamientos e intervenciones médicas», La Ley, Derecho de Familia, vol. 13, 2017, pp. 1-11.

RIVERA ÁLVAREZ, J. M., «El consentimiento informado del adolescente en situaciones de grave riesgo: ¿Autonomía privada vs. interés superior del menor?» $R D P$, vol. 2, 2015, pp. 71-88.

RIVERO HERNÁNDEZ, F., El interés del menor, Madrid (Dykinson), 2000.

ROCA TRÍAS, E., «El interés del menor como factor de progreso y unificación», $R J C$, vol. 93, núm. 4, 1994, pp. 101-122.

RUIZ-RICO RUIZ-MORÓN, J., «Ultimas reformas de las instituciones privadas de protección de menores y la filiación por la Ley 26/2015, de modificación del sistema de protección a la infancia y la adolescencia», Revista Doctrinal Aranzadi civil-mercantil, vol. 3, 2015, pp. 1-18.

SANTOS MORÓN, M.J., «Menores y derechos de la personalidad. La autonomía del menor», AFDUAM, vol. 15, 2011, pp. 63-93.

TORRES PEREA, J., Interés del menor y Derecho de familia. Una perspectiva multidisciplinar, Madrid (Iustel), 2009. 